\title{
WELFARE IMPLICATIONS OF THE RENEWABLE FUEL STANDARD WITH AN INTEGRATED TAX-SUBSIDY POLICY
}

Abstract

4 This paper derives the optimal integrated tax-subsidy policy where one input is taxed and reve-

5 nues are used to subsidize the use of a substitute input to reduce greenhouse gas emissions given

6 the existing policies under the Renewable Fuel Standard policies. We measure the welfare effects

7 and impact on cellulosic ethanol production after implementing the tax-subsidy policy using a

8 general equilibrium model. A revenue-neutral integrated tax-subsidy scheme would lead to a

9 small positive tax rate for crude oil and a large positive subsidy for cellulosic ethanol because the

10 former has a larger emissions coefficient than the latter. The overall welfare effects of an inte-

11 grated tax subsidy scheme are less than a $1 \%$ increase for the economy but the growth in the cel-

12 lulosic ethanol industry could range from $28 \%$ to $238 \%$ because the revenues from taxing crude

13 oil are directly used to subsidize cellulosic ethanol production.

14 Keywords: Renewable Fuel Standard, Carbon Tax, Revenue-neutral

15 JEL Codes: H23, Q48, Q16, Q43 


\section{Introduction}

2 A carbon tax is one of the programs considered and developed to reduce greenhouse gas (GHG)

3 emissions. Several countries have implemented national carbon taxes such as Denmark (IEA

4 2002), Sweden (Hammar and Jagers 2007), Finland (Vourc'h and Jimenez 2000) and parts of

5 Canada (British Columbia Ministry of Small Business and Revenue 2008). Carbon taxes are

6 touted by economists as an effective instrument in addressing climate change (Tol 2005). How-

7 ever, political concerns hindered significant traction at the federal level in the United States

8 (Metcalf 2009).

9 When the revenue from a carbon tax is used to offset an existing distortionary tax policy or it

10 is used to subsidize relatively cleaner technology, public support for carbon taxes across political

11 groups increase drastically (Amdur et al. 2014). Feebates are an example of a pollution tax where

12 the revenues are used to subsidize the use of less polluting or clean good. In the energy market in

13 Gainesville, Florida, a surcharge on consumption of electricity is collected and the ensuing reve-

14 nues are used to fund the purchase of electricity generated by privately owned solar panels (New

15 York Times 2009). In the automotive market, taxes are imposed on low mileage cars and a tax

16 rebate is imposed on high mileage cars (Greene et al. 2005). Such policies shift consumption to-

17 ward goods that are relatively less polluting (Johnson 2006).

18 The US government enacted the Energy Independence and Security Act (EISA) of 2007 as

19 an attempt to reduce fossil fuel dependence by increasing renewable fuel and as a way to reduce

20 GHG emissions by substituting for feedstock that has a relatively lower emissions coefficient.

21 The law provides incentives to increase conventional biofuel production from feedstocks such as

22 sugar or starch as well as advanced biofuels using cellulosic feedstocks such as woody crops or

23 agricultural residue. EISA mandates an increasing role for cellulosic biofuel use such that by

242022,16 billion gallons are required to be used which is larger than the 15-billion-gallon con- 
sumption mandate for conventional biofuel (GPO 2011).

2 Even with a growing emphasis on cellulosic biofuels relative to conventional biofuels, the

3 production of the cellulosic biofuel is slow. Only 20,069 gallons of cellulosic biofuel were pro-

4 duced in 2012, despite an original mandate of 0.5 billion gallons (EPA 2013). There are two re-

5 levant Renewable Fuel Standard (RFS) policies related to the cellulosic biofuel requirement: the

6 input ratio requirement which imposes a lower bound on the amount of cellulosic fuel used in

7 production and the price of waivers which can be used to circumvent the input requirement (Sko-

8 lrud and Galinato 2015). Given the political feasibility of pollution taxes where the revenues

9 subsidize less polluting substitute goods, an interesting question arises: How will such a tax-

10 subsidy system affect welfare in the presence of the existing RFS policies that incentivize cellu-

$11 \quad$ losic fuel production?

12 The objective of this article is to determine the effect on welfare and cellulosic fuel produc-

13 tion from an integrated tax-subsidy policy that reduces GHG emissions given the existing RFS

14 policies related to the cellulosic biofuel requirements. We develop a general equilibrium model

15 of GHG based subsidies for low carbon emitting energy inputs such as cellulosic fuel that are

16 funded solely by taxes on high energy carbon emitting sources such as crude oil. This approach

17 alleviates concerns regarding implementation of taxes only or subsidies only since the policy can

18 be revenue-neutral where aggregate additional tax revenues is zero and no new expenditures are 19 added.

20 We contribute to the literature in two ways. First, this is the first paper that solves for the op-

21 timal integrated tax-subsidy policy in a general equilibrium framework. Galinato and Yoder

22 (2010) developed a partial equilibrium framework that analyzed the optimal derivation of taxes

23 and subsidies across various energy output sources. We extend their model by using a general

24 equilibrium framework with multiple sectors and incorporating the integrated tax-subsidy 
1 framework in the use of inputs that are blended in the production of fuel. Second, by incorporat-

2 ing the integrated tax-subsidy framework on top of the current RFS policies, we are able to de-

3 termine the extent to which the integrated tax-subsidy policy can boost cellulosic biofuel produc-

4 tion. We calibrate and simulate the model for Washington State, Idaho and Oregon - states with

5 varying abundance of cellulosic feedstock in the form of woody biomass (Yoder et al. 2010).

6 In a partial equilibrium framework, the standard Pigouvian tax rate is equal to marginal dam-

7 ages created by the pollutant and independent of emissions from other sectors in the economy

8 (Sandmo 1975; Kopczuk 2003). Galinato and Yoder (2010) was the first paper to model the fee-

9 bate structures by formally deriving the optimal output tax-subsidy schedules from an optimiza-

10 tion model. They show that output taxes and subsidies across sectors are not separable because

11 the magnitude and sign of a tax on one form of energy depends in part on the relative emissions

12 of the other energy sources. We extend the analysis by determining the effect on the input mix

13 when the integrated tax subsidy framework is used to incentivize use of a relatively cleaner input

14 (cellulosic fuel) to produce blended fuel rather than a more polluting source (crude oil). Also,

15 unlike Galinato and Yoder (2010), we solve the integrated tax-subsidy schedule using a general

16 equilibrium framework as opposed to a partial equilibrium model to capture any potential spil-

17 lover effects from other sectors in the production chain.

18 The integrated tax-subsidy framework has some similarities to the double-dividend literature

19 where pollution taxes are imposed on dirty goods and revenues are used to reduce the rate of a

20 pre-existing distortionary tax such as an income tax (Parry 1998), but there are key differences.

21 First, the double-dividend literature usually uses labor as a revenue source and a destination for

22 subsidies but in our case, labor only plays an indirect role because the tax and subsidized inputs

23 are all in one sector of the economy. Second, the double-dividend literature does not solve any

24 optimal subsidy level for the pre-existing distortionary tax since the market is usually assumed to 
not have any externalities related to it. In our case, not only do we solve for the optimal tax on

2 the polluting input, but we also solve for the optimal subsidy of a cleaner input because it may be

3 possible that the cleaner input yields pollution albeit at a lower level than the dirtier input.

4 The renewable fuel mandate set by the EPA is an input pollution standard. The input pollu-

5 tion standard is second only to output standards in curbing total production of a dirty firm (Hel-

6 fand 1991). The standard is imposed as an input ratio mandate, which requires cellulosic biofuel

7 to be used in production equal to a percentage of the nonrenewable fuel used in production. In

82014 this percentage was set at approximately $0.02 \%$, rising to $0.128 \%$ by 2016 (EPA 2016). ${ }^{1}$

9 When cellulosic production is insufficient, fuel producers can buy waiver credits to satisfy their

10 cellulosic RFS obligation (GPO 2011). Purchasing one waiver credit is equivalent to using a gal-

11 lon of cellulosic biofuel, and is priced at the greater of $\$ .25$ and $\$ 3.00$ minus the wholesale price

12 of gasoline (GPO 2011). These two instruments together have led to low cellulosic production

13 even when the input-ratio requirement is raised because firms have the option to purchase waiv-

14 ers instead (Skolrud et al. 2014). Skolrud and Galinato (2015) integrate a revenue-neutral tax into

15 a general equilibrium framework where crude oil use is taxed and the revenues are used to re-

16 duce a sales tax in Washington and an income tax in Oregon. However, they do not consider in-

17 centivizing adoption of alternative inputs in fuel blending such as subsidizing cellulosic ethanol

18 production.

19 We modify the general equilibrium model developed by Skolrud et al. (2014) to solve for the

20 optimal tax-subsidy mechanism in the presence of the RFS policy. Our theoretical model shows

21 that when a constraint on tax revenues are implemented, the marginal welfare from the targeted

\footnotetext{
${ }^{1}$ These percentages have been adjusted downwards by the EPA to account for limited cellulosic biofuel production (EPA 2016). In 2016, the percentage standard specified by the RFS legislation was set at approximately $2.6 \%$, rising to over $9 \%$ by 2022 . A $9 \%$ standard at current fuel consumption is equivalent to approximately 16 billion gallons of cellulosic biofuel (GPO 2011).
} 
1 tax is introduced in the optimal conditions creating a smaller tax rate for crude oil and a subsidy

2 for cellulosic fuel. Numerical simulations indicate that the imposition of such a mechanism

3 would be welfare improving in Washington. In the unconstrained tax revenue case, we find that

4 the tax on crude oil ranges between $\$ 0.35 /$ gallon and $\$ 0.74$ /gallon, while the optimal tax on cel-

5 lulosic biofuel ranges from $\$ 0.12 /$ gallon to $\$ 0.51 /$ gallon. The optimal unconstrained tax rates are

6 larger than the Pigouvian level to account for additional distortions due to input substitution, im-

7 perfect competition and the existence of waiver credits. When a targeted net tax revenue of zero

8 is imposed, the crude oil tax shrinks significantly, ranging from $\$ 0.00006 /$ gallon to

$9 \$ 0.0005 /$ gallon, while the tax on cellulosic biofuel turns to a subsidy, which ranges from

$10 \$ 0.41 /$ gallon to $\$ 1.28 /$ gallon. The disparity in magnitude and sign between the taxes is due to the

11 lower emission coefficient of cellulosic biofuel compared to crude oil and the low input ratio be-

12 tween cellulosic biofuel and crude oil. If such an integrated tax-subsidy policy is implemented,

13 cellulosic biofuel usage increases by $28 \%$ to $238 \%$ but overall social welfare increases by less

14 than $1 \%$. While our model is calibrated and simulated for three states in the Pacific Northwest,

15 we provide an additional simulations that generalize our results for other regions with varying

16 endowments of cellulosic ethanol feedstocks.

\section{2. Model}

18 Our general equilibrium model has six sectors which include two feedstock sectors, a cellulosic

19 refining sector, a blended fuel sector, a composite good sector, and a consumer sector. The out-

20 put from the two feedstock sectors, the agricultural and forest sectors, can either be used as in-

21 puts for the production of cellulosic biofuel in the cellulosic refining sector or used by the com-

22 posite good sector to produce a final good. ${ }^{2}$ The blended fuel sector, in turn, purchases the cellu-

\footnotetext{
${ }^{2}$ While cellulosic feedstock can be refined into different types of biofuel, refiners have focused on cellulosic ethanol in particular, which is reflected in our theoretical and numerical analysis.
} 
1 losic ethanol along with crude oil to produce blended fuel while facing the input ratio mandate

2 and waiver credit policies in the RFS. Finally, consumers purchase fuel and a composite con-

3 sumption good. Production of blended fuel emits pollution which is harmful to the consumer.

4 The government corrects this externality using a revenue-neutral, integrated tax-subsidy policy

5 that taxes the dirty input and subsidizes the clean input. Figure 1 summarizes the relationship be-

6 tween sectors in the model and highlights the various interdependencies between the sectors of

7 the model.

\section{$8 \quad 2.1$ Sectors in the Economy}

9 We model the behavior of each agent in the six sectors in the economy.

\section{$10 \quad 2.1 .1 \quad$ Consumption sector}

11 The representative consumer derives utility from blended fuel, $B$, and composite good, $X$.

12 Emissions from blended fuel production, $E$, create disutility for the consumer. Utility is,

$$
U(B, X, E)=u(B, X)-\delta E,
$$

14 where $u(\bullet)$ is an increasing and concave sub-utility function and $\delta$ is the marginal disutility of

15 pollution. Total emissions from blended fuel production depends on aggregate emission intensi-

16 ties from the use of crude oil, $Y_{i}^{o}$, and cellulosic ethanol, $Y_{i}^{c}$, by all firms in the blended fuel sec-

17 tor, $E=e^{c} \sum_{i=1}^{n} Y_{i}^{c}+e^{o} \sum_{i=1}^{n} Y_{i}^{o}$, where the emissions coefficient for crude oil is higher than for

18 cellulosic ethanol, $e^{o}>e^{c}$ (Galinato and Yoder 2010).

19 Consumers own all resources in the economy. Thus, the consumer's budget constraint is,

$$
p^{b} B+X=r K+w L+m R+\pi^{x},
$$

21 where $p^{b}$ is the price of blended fuel, $r$ is the rental rate of capital, $K$ is the consumer's capital

22 endowment, $w$ is the wage rate, $L$ is fixed labor supply, $m$ is the rental rate of land, $R$ is the 
consumer's land endowment, and $\pi^{x}$ are the profits from blended fuel production. We normalize

2 the price of the composite good to 1.

3 The conditions that maximize (1) subject to (2) are the budget constraint (2) along with the

4 condition stating that the marginal rate of substitution equals relative prices,

$$
\frac{u_{B}}{u_{X}}=p^{b}
$$

6 Solving equation (3) simultaneously with the budget constraint leads to the demand functions

$7 \quad B^{*}\left(p^{b}, I\right)$ and $X^{*}\left(p^{b}, I\right)$, where $I=r K+w L+m R+\pi^{x}$.

\subsubsection{Blended fuel sector}

9 Firm $i$ in the blended fuel sector chooses labor, $L_{i}^{b}$, capital, $K_{i}^{b}$, crude oil, $Y_{i}^{o}$, and cellulosic

10 ethanol, $Y_{i}^{c}$, to produce blended fuel, $Y_{i}^{b}$, using the production function $Y_{i}^{b}=Y_{i}^{b}\left(K_{i}^{b}, L_{i}^{b}, Y_{i}^{c}, Y_{i}^{o}\right)$

11.3 Blended fuel output is increasing and concave in all the arguments. Also, we assume that crude

12 oil is produced exogenously outside the economy. We model the $n$ firms as competing in a

13 Cournot oligopoly. ${ }^{4}$ Each firm takes input prices as given and solves the following:

$$
\begin{aligned}
\max _{\left\{K_{i}^{b}, L_{i}^{b}, Y_{i}^{c}, Y_{i}^{o}, W_{i}\right\}} \pi_{i}= & p^{b}\left(\sum_{i=1}^{n} Y_{i}^{b}\left(K_{i}^{b}, L_{i}^{b}, Y_{i}^{c}, Y_{i}^{o}\right)\right) Y_{i}^{b}\left(K_{i}^{b}, L_{i}^{b}, Y_{i}^{c}, Y_{i}^{o}\right) \\
& -r K_{i}^{b}-w L_{i}^{b}-\left(p^{c}+\tau^{c}\right) Y_{i}^{c}-\left(p^{o}+\tau^{o}\right) Y_{i}^{o}-W_{i},
\end{aligned}
$$

15 where $p^{b}(\bullet)$ is the inverse demand curve for blended fuel, $p^{c}$ and $p^{o}$ are the respective prices

16 of cellulosic ethanol and crude oil, $\tau^{c}$ and $\tau^{o}$ are the respective taxes and/or subsidies for cellu-

\footnotetext{
${ }^{3}$ Using $i$ subscript notation for the blended fuel sector is the only deviation from our practice of using subscripts as notation for partial derivatives. In referring to the partial derivative of an $i$-subscripted variable, we use explicit notation, e.g. $\partial \pi_{i} / \partial Y_{i}^{c}$ to express the partial derivative of the profit of firm $i$ with respect to its use of cellulosic ethanol. ${ }^{4}$ We model the blended fuel sector as an oligopoly to be appropriate for the case of Washington State. The Pacific Northwest is largely served by five blended fuel producers (oil refineries). While collusive behavior has not been formally identified, the sector was investigated in 2008 by the Washington State Attorney General on suspicion of collusion (Washington State Office of the Attorney General 2016).
} 
1 losic ethanol and crude oil, and $W_{i}$ is the firm's expenditure on waiver credits.

2 Maximization of (4) is subject to the Renewable Fuel Standard (RFS) constraint that a per-

3 centage of cellulosic ethanol must be purchased depending on the total amount of crude oil used

4 in production. Each firm has two ways of satisfying this constraint: they can either use enough

5 cellulosic ethanol $\left(Y_{i}^{c}\right)$ in the production process, or purchase waiver credits $\left(W_{i} / g\right)$ (GPO

6 2011). The constraint can be represented as,

$7 \quad(5)$

$$
Z^{c} Y_{i}^{o}=Y_{i}^{c}+\frac{W_{i}}{g}
$$

where $Z^{c}$ is the RFS percentage standard for cellulosic ethanol and $g$ is the waiver credit price.

9 The waiver credit price is set by the EPA as the higher value between $\$ 0.25$ and the average an-

10 nual wholesale price of gasoline per gallon minus \$3 (GPO 2011). Cellulosic biofuel is the only

11 type of biofuel specified by the RFS to be eligible for waiver credits (Skolrud and Galinato

12 2015).

13 The first-order conditions for an interior solution to the firm's profit maximization problem

14 in (4) after substituting in the RFS constraint in (5) are given by,

$15(6)$

$$
\begin{aligned}
& \frac{\partial \pi_{i}^{x}}{\partial K_{i}^{b}}=p^{b} \frac{\partial Y^{b}}{\partial K_{i}^{b}}\left(\frac{1}{n \dot{o}^{b}}+1\right)-r=0, \\
& \frac{\partial \pi_{i}^{x}}{\partial L_{i}^{b}}=p^{b} \frac{\partial Y^{b}}{\partial L_{i}^{b}}\left(\frac{1}{n \dot{o}^{b}}+1\right)-w=0, \\
& \frac{\partial \pi_{i}^{x}}{\partial Y_{i}^{c}}=p^{b} \frac{\partial Y^{b}}{\partial Y_{i}^{c}}\left(\frac{1}{n \dot{o}^{b}}+1\right)-\left(p^{c}+\tau^{c}-g\right)=0, \\
& \frac{\partial \pi_{i}^{x}}{\partial Y_{i}^{o}}=p^{b} \frac{\partial Y^{b}}{\partial Y_{i}^{o}}\left(\frac{1}{n \dot{o}^{b}}+1\right)-\left(p^{o}+\tau^{o}+g Z^{c}\right)=0,
\end{aligned}
$$

16 where $\dot{o}^{b} \equiv\left(d B / d p^{b}\right)\left(p^{b} / B\right)$ is the price elasticity of demand for blended fuel. Other firms in

17 the sector have similar first order conditions. Simultaneously solving all the first order conditions 
from the $i$ firms yield the best response functions.

2 Each equation shows the marginal revenue of each input equals its marginal cost. The mar-

3 ginal cost of crude oil includes the input ratio requirement and the tax level. For cellulosic etha-

4 nol, input use entails an addition in marginal revenue in the form of the waiver price. Note the

5 complementary impact that the taxes and RFS policy variables have in the first-order conditions

6 for cellulosic ethanol and crude oil. An increase in $\tau^{o}$ leads to the same effect as an increase in $g$

7 or $Z^{c}$ by an equivalent magnitude. On the other hand, an increase in $\tau^{c}$ yields the exact same

8 effect as a decrease in $g$ of the same magnitude. The RFS input ratio and waiver credit system

9 can be perfectly replicated through the appropriate selection of $\tau^{c}$ and $\tau^{o}$. To see this, set $\tau^{c}$

10 equal to the negative of the waiver price $g$, and then set $\tau^{o}$ equal to the waiver price multiplied

11 by the percentage standard, $g Z^{c}$, in the equations in (6). This implies that the optimal tax policy

12 for each input can be adjusted to fully internalize any remaining externality that the RFS policy

13 fails to correct.

\section{$14 \quad 2.1 .3 \quad$ Cellulosic refining sector}

15 A representative firm in the perfectly competitive cellulosic refining sector chooses capital, $K^{c}$,

16 labor $L^{c}$, cellulosic feedstock from the agricultural and forestry sectors, $Y^{a}$ and $Y^{f}$, to produce

17 cellulosic ethanol, $Y^{c}$, in accordance with the production function $Y^{c}=Y^{c}\left(K^{c}, L^{c}, Y^{a}, Y^{f}\right)$. Out-

18 put is increasing and concave in all arguments. First-order conditions for the representative

19 firm's maximization problem are given by:

20

$$
\begin{aligned}
& p^{c} Y_{K^{c}}^{c}\left(K^{c}, L^{c}, Y^{a}, Y^{f}\right)-r=0, \\
& p^{c} Y_{L^{c}}^{c}\left(K^{c}, L^{c}, Y^{a}, Y^{f}\right)-w=0, \\
& p^{c} Y_{Y^{a}}^{c}\left(K^{c}, L^{c}, Y^{a}, Y^{f}\right)-p^{a}=0, \\
& p^{c} Y_{Y^{f}}^{c}\left(K^{c}, L^{c}, Y^{a}, Y^{f}\right)-p^{f}=0,
\end{aligned}
$$


1 where $p^{a}$ and $p^{f}$ are the prices of cellulosic feedstock from the agriculture and forestry sectors

2 respectively. The value of marginal product of each input equals its input price.

$3 \quad 2.1 .4$ Cellulosic feedstock sectors and the composite good sector

4 Production of cellulosic feedstock occurs in the agricultural and forestry sectors, both of which

5 utilize capital, labor, and land as inputs. Similarly, production of the other final good, which

6 represents a composite good of all remaining goods in the model economy, utilize the same in-

7 puts. Production in each competitive sector is characterized by the production function

$8 Y^{s}=Y^{s}\left(K^{s}, L^{s}, R^{s}\right), \forall s=a, f$,x. First-order conditions from profit maximization are,

$$
\begin{aligned}
& p^{s} Y_{K^{s}}^{s}\left(K^{s}, L^{s}, R^{s}\right)-r=0, \\
& p^{s} Y_{L^{s}}^{s}\left(K^{s}, L^{s}, R^{s}\right)-w=0, \\
& p^{s} Y_{R^{s}}^{s}\left(K^{s}, L^{s}, R^{s}\right)-m=0,
\end{aligned}
$$

10 for all $s=a, f, \mathrm{x}$. Equilibrium entails the value of marginal product equals its input price.

\section{$11 \quad 2.2 \quad$ Equilibrium}

12 The equilibrium conditions that solve the model consists of the first-order conditions from each

13 sector, represented by equations (2) and (3), the four equations in (6), the four equations in (7),

14 the nine equations in (8), and the following eight market clearing conditions, 


$$
\begin{aligned}
& \sum_{i=1}^{n} Y_{i}^{b}=B, \\
& Y^{x}\left(K^{x}, L^{x}, R^{x}\right)=X, \\
& \sum_{i=1}^{n} Y_{i}^{c}=Y^{c}\left(K^{c}, L^{c}, Y^{a}, Y^{f}\right), \\
& Y^{s}=Y^{s}\left(K^{s}, L^{s}, R^{s}\right), \forall s=a, f, \\
& \sum_{i=1}^{n} K_{i}^{b}+K^{x}+K^{c}+K^{a}+K^{f}=K, \\
& \sum_{i=1}^{n} L_{i}^{b}+L^{x}+L^{c}+L^{a}+L^{f}=L, \\
& R^{a}+R^{f}+R^{x}=R .
\end{aligned}
$$

2 The equilibrium definition admits a set of 27 equations in 27 unknowns, a system which will be

3 solved simultaneously in our numerical simulations.

\section{3. Optimal taxes}

5 To mitigate the pollution externality, the government maximizes social welfare by choosing the optimal tax levels for each polluting input. We consider two tax scenarios. The first uses uncon-

7 strained tax revenue while the second scenario constrains the tax revenue to an exogenous target.

8 The latter case allows us to analyze the effect of a revenue-neutral tax system.

$9 \quad 3.1 \quad$ Environmental tax with unconstrained revenues

10 Social welfare is the sum of consumer surplus, profits from fuel blending, tax revenues including

11 waiver expenditures, less the disutility from pollution. The government's objective is to maxim-

12 ize social welfare by choosing taxes,

$$
\max _{\left\{\tau^{c}, \tau^{o}\right\}} \Omega=A+\pi^{b}+\tau^{c} Y^{c}+\tau^{o} Y^{o}+W-\delta E
$$

14 where $A=u\left(B^{*}\left(p^{b}, I\right), X^{*}\left(p^{b}, I\right)\right)-p^{b} B-X$ is the consumer surplus, $\pi^{b}=\sum_{i=1}^{n} \pi_{i}^{b}$ is aggregate

15 profits in the blended sector, $Y^{c}=\sum_{i=1}^{n} Y_{i}^{c}$ is aggregate output in cellulosic ethanol, 
$1 \quad Y^{o}=\sum_{i=1}^{n} Y_{i}^{o}$ is aggregate crude oil use, and $W=\sum_{i=1}^{n} W_{i}$ is aggregate waivers purchased. Profit

2 in the composite good sector is zero because we assume constant returns to scale and perfect

3 competition. The first-order conditions are given by:

$$
\Omega_{\tau^{k}}=A_{\tau^{k}}+\pi_{\tau^{k}}^{b}+Y^{k}+\tau^{k} Y_{\tau^{k}}^{k}+\tau^{l} Y_{\tau^{k}}^{l}+W_{\tau^{k}}-\delta\left(e^{k} Y_{\tau^{k}}^{k}+e^{l} Y_{\tau^{k}}^{l}\right)=0 \text {, for } k=c, o \text { s.t. } k \neq l,
$$

5 where subscripts on $Y^{k}$ indicate partial derivatives of the aggregate quantity $Y^{k}$ with respect to

6 the subscripted argument. From the envelope theorem, $\partial \pi^{b} / \partial \tau^{k}=-Y^{k}$ for $k=c, o$ s.t. $k \neq l$. The

7 unconstrained tax will deviate from the Pigouvian expression ${ }^{5}$ due to the impact of the tax rate

8 on consumer surplus, $A_{\tau^{k}}$, through its impact on the oligopolistic blended fuel price and from the

9 impact of the tax rate on waiver expenditures, $W_{\tau^{k}}$. Solving the first-order conditions yields the

10 optimal unconstrained tax rates, $\tilde{\tau}^{k}:^{6}$

$$
\tilde{\tau}^{k}=\delta e^{k}+\underbrace{\frac{Y_{\tau^{k}}^{l}}{Y_{\tau^{k}}^{k} Y_{\tau^{l}}^{l}-Y_{\tau^{k}}^{l} Y_{\tau^{l}}^{k}}}_{(+)}\left(W_{\tau^{l}}+A_{\tau^{l}}\right)-\underbrace{\frac{Y_{\tau^{l}}^{l}}{Y_{\tau^{k}}^{k} Y_{\tau^{l}}^{l}-Y_{\tau^{k}}^{l} Y_{\tau^{l}}^{k}}}_{(-)}\left(W_{\tau^{k}}+A_{\tau^{k}}\right) \text {, for } k=c, o \text { s.t. } k \neq l .
$$

12 The tax can be partitioned in two parts, the typical Pigouvian expression, $\delta e^{k}$, and expressions

13 that captures the effect of changes in both tax rates on waiver expenditures and consumer sur-

14 plus. The latter terms are difficult to sign, but we can draw inference from its components, allow-

15 ing us to understand the sensitivity of waiver expenditures and consumer surplus to pollution

16 taxes and the RFS policy variables.

17 As we show below, the last two terms of equation (12) correct for the own and cross tax ef-

18 fects on fuel inputs, the market power in blended fuel sector and the subsidizing effect of the

\footnotetext{
${ }^{5}$ If the effect of the taxes on consumer surplus and the impact on waiver expenditures are both zero, i.e. $\left(A_{t}{ }^{k}=0\right)$ and $\left(W_{\tau^{k}}=0\right)$, we can solve the first-order conditions in (11) to yield the typical Pigouvian tax expression, $\tau^{k}=\delta e^{k}$ for $k=c, o$, which equates the optimal tax rate to the marginal environmental damage to consumers.

${ }^{6}$ See Appendix, Section A.1 for full derivation.
} 
1 waiver credits in using fossil fuel. The own and cross tax effects on fuel inputs magnify the net

2 effect from market power and waiver credit channels. We expect an increase in the optimal crude

3 oil tax to have a negative impact on waiver expenditures and an increase in the optimal cellulosic

4 ethanol tax to have a positive impact. We show that more market power, as proxied by the

5 change in consumer surplus, reduces the tax. If the effect through waiver credits outweighs the

6 effect through market power, the optimal environmental tax may be higher than the Pigouvian

7 level.

8 The second term in equation (12) expresses the effect of the other polluting good tax, $\tau^{l}$, on

9 waiver expenditures and consumer surplus $\left(W_{\tau^{l}}+A_{\tau^{l}}\right)$, while the third term captures the impact

10 of the own-good tax, $\tau^{k}$, on waiver expenditures and consumer surplus $\left(W_{\tau^{k}}+A_{\tau^{k}}\right)$. Each of

11 these effects is multiplied by a factor composed of marginal effects of the two taxes on cellulosic

12 ethanol and crude oil inputs, i.e. $Y_{\tau^{k}}^{l} /\left(Y_{\tau^{k}}^{k} Y_{\tau^{l}}^{l}-Y_{\tau^{k}}^{l} Y_{\tau^{l}}^{k}\right)$ and $Y_{\tau^{l}}^{l} /\left(Y_{\tau^{k}}^{k} Y_{\tau^{l}}^{l}-Y_{\tau^{k}}^{l} Y_{\tau^{l}}^{k}\right)$. If the cross-tax

13 effects, $\tau_{k}^{l}$, for $k=c, o$ s.t. $k \neq l$ are positive and the absolute value of the product of own-tax

14 effects outweighs the absolute value of the cross-tax effects, $Y_{\tau^{k}}^{k} Y_{\tau^{l}}^{l}-Y_{\tau^{\prime}}^{l} Y_{\tau^{\prime}}^{k}>0$, then increases in

15 the sensitivity of waiver expenditures and consumer surplus to the pollution taxes lead to a larger

16 deviation in the optimal revenue-unconstrained tax from the typical Pigouvian expression. The

17 optimal tax may be higher or lower than the Pigouvian level depending on the effect through

18 waiver expenditures and market power as proxied by changes in consumer surplus.

19 The crude oil tax and cellulosic ethanol tax has varying effects on waiver credit expenditures,

$W_{\tau^{c}}=g\left(Z^{c} Y_{\tau^{c}}^{o}-Y_{\tau^{c}}^{c}\right)>0$.

$$
\begin{gathered}
W_{\tau^{o}}=g\left(Z^{c} Y_{\tau^{o}}^{o}-Y_{\tau^{o}}^{c}\right)<0, \\
(-) \quad(+) \\
W_{\tau^{c}}=g\left(Z^{c} Y_{\tau^{c}}^{o}-Y_{\tau^{c}}^{c}\right)>0 .
\end{gathered}
$$

$$
(+) \quad(-)
$$

21 This is an intuitive result: as the crude oil tax increases, less crude oil is used as an input in 
1 blended fuel production, which decreases the RFS requirement for cellulosic ethanol usage, $Z^{c}$,

2 subsequently requiring the purchase of fewer waivers. Similarly, an increase in the cellulosic

3 ethanol tax increases waiver expenditures because as the tax increases, cellulosic ethanol use de-

4 clines, requiring more waiver purchases to meet the RFS mandate.

5 The direct effect of the RFS policy variables on the optimal tax rates operate through their

6 impact on the sensitivity of waiver expenditures to the tax rates. From equation (13), we observe

7 that the direct effect of increases in the waiver price, $g$, or the percentage standard, $Z^{c}$, on $W_{\tau^{\circ}}$

8 is negative, and the effect on $W_{\tau^{c}}$ is positive. Thus, the direct impact from either policy variable

9 on the optimal tax rate is ambiguous.

10 The impact of the tax on consumer surplus, $A_{\tau^{k}}$, is given by $-B\left(\partial p^{b} / \partial \tau^{k}\right){ }^{7}$ The sign de-

11 pends critically on the impact of the tax on the price of blended fuel. Since the price of blended

12 fuel is determined by an oligopoly and an increase in the tax rate results in an increase in each

13 firm's marginal cost, we expect that an increase in either the crude oil or cellulosic ethanol tax

14 will result in a reduction of output and an increase in the blended fuel price, so $A_{\tau^{k}}<0$, for

$15 k=c, o$. This market power effect decreases the optimal environmental tax.

16 Given the individual effects we have outlined, we can finally make an inference about the 17 overall sign of equation (12). While it is clear that $W_{\tau^{o}}+A_{\tau^{o}}<0$, the sign of $W_{\tau^{c}}+A_{\tau^{c}}$ is less cer-

18 tain. If $\left|W_{\tau^{c}}\right|<\left|A_{\tau^{c}}\right|$, then the net effect of the second and third term in equation (12) is negative.

19 In this case, the combined effect of the oligopoly market power and the waiver credit reduces

20 output closer to the socially optimal level compared to the case with a perfectly competitive

21 market and no waiver credits. Thus, the optimal tax rate required to reach the socially optimal

22 level of production of blended fuel is lower than the Pigouvian rate. However, if $\left|W_{\tau^{c}}\right| \geq\left|A_{\tau^{c}}\right|$, the

\footnotetext{
${ }^{7}$ See Appendix, Section A.3 for derivation.
} 
1 sign of the summation of the two terms in equation (12) is ambiguous. The optimal revenue-

2 unconstrained tax may be higher than the Pigouvian rate if waiver expenditures are significantly

3 more sensitive to the tax rates relative to the change in consumer surplus from the market power

4 effect.

$5 \quad 3.2$ Revenue-neutral environmental tax

6 When a revenue-neutral constraint is imposed, the government's objective function remains the

7 same, but now an additional constraint is added to the maximization problem. So we have:

8

$$
\max _{\left\{\tau^{c}, \tau^{o}\right\}} \Omega=A+\pi^{b}+\tau^{c} Y^{c}+\tau^{o} Y^{o}+W-\delta E,
$$

s.t. $T=\tau^{c} Y^{c}+\tau^{o} Y^{o}$,

9 where $T$ is an exogenous tax target. If a revenue-neutral tax target is preferred, then $T=0$. The

10 first order conditions that solve the problem include the constraint along with the conditions,

$$
\begin{aligned}
\mathrm{L}_{\tau^{k}} & =A_{\tau^{k}}+\pi_{\tau^{k}}^{b}+Y^{k}+\tau^{k} Y_{\tau^{k}}^{k}+\tau^{l} Y_{\tau^{k}}^{l}+W_{\tau^{k}}-\delta\left(e^{k} Y_{\tau^{k}}^{k}+e^{l} Y_{\tau^{k}}^{l}\right) \\
& -\lambda\left(\tau^{k} Y_{\tau^{k}}^{k}+Y^{k}+\tau^{l} Y_{\tau^{k}}^{l}\right)=0, \text { for } k=c, o \text { s.t. } k \neq l,
\end{aligned}
$$

12 where $\lambda$ is the Lagrangian multiplier that measures the marginal social welfare of relaxing the

13 tax-revenue $\operatorname{target} T$.

14 Following similar algebraic steps as in the derivation of the unconstrained tax, we can write

15 the optimal revenue-constrained tax, denoted by $\hat{\tau}^{k}$, as:

16

$$
\begin{aligned}
& \hat{\tau}^{k}=\frac{\delta}{1-\lambda^{*}(T)} e^{k}+\frac{1}{Y_{\tau^{k}}^{k} Y_{\tau^{l}}^{l}-Y_{\tau^{l}}^{k} Y_{\tau^{k}}^{l}}\left(Y_{\tau^{k}}^{l} \frac{W_{\tau^{l}}+A_{\tau^{l}}-\lambda^{*} Y^{l}}{1-\lambda^{*}(T)}-Y_{\tau^{l}}^{l} \frac{W_{\tau^{k}}+A_{\tau^{k}}-\lambda^{*} Y^{k}}{1-\lambda^{*}(T)}\right), \\
& \text { for } k=c, o \text { s.t. } k \neq l,
\end{aligned}
$$

17 where $\lambda^{*}(T)$ represents the optimal $\lambda$ (which is a function of $T$ ) that solves the system of first- 
1 order conditions. ${ }^{8}$ Similar to Galinato and Yoder (2010), each tax rate is increasing in $T$ as long

2 as $T<T^{*}$ where $T^{*}$ is aggregate tax revenue from the unconstrained tax case. In fact, if $T=0$,

3 one input is taxed while the other is subsidized. As the tax target increases, the positive tax rate

4 increases while the subsidy decreases.

5 Unlike Galinato and Yoder (2010) who consider an output tax and perfectly competitive

6 markets, we find two other effects when considering an input tax in an imperfect market. First,

7 since the tax rate also accounts for the distortions from market power and the waiver credit, it

8 may be the case that the more pollution intensive input, crude oil, is subsidized while the less

9 pollution intensive input, cellulosic ethanol, is taxed. This would occur if the reduction in waiver

10 expenditure from the use of crude oil is large and the government considers waiver credits a sig-

11 nificant source of revenues. Second, since we impose an input tax instead of an output tax, the

12 output price's role is only confined to its impact on consumer surplus changes due to the tax rate.

13 If the price is not sensitive to tax changes, consumer surplus will not be affected even when $T$

14 increases which implies that the change in the integrated tax-subsidy rates are not as large. In our

15 numerical simulations, we focus our analysis on the revenue-neutral case where $T=0$.

\section{4. Numerical simulation}

17 We describe the data and functional form assumptions used in the simulation and calibration

18 techniques for Washington State, Idaho and Oregon.

\section{$19 \quad 4.1 \quad$ Functional forms and parameters}

20 A constant elasticity of substitution (CES) functional form is used in all sectors. CES production

21 functions are chosen to capture differences in input substitutability between the productive sec-

22 tors. The CES form also has a sufficient number of parameters for the model calibration based on

\footnotetext{
${ }^{8}$ Refer to Appendix A.2 for complete derivation and the full expression of $\lambda^{*}(T)$.
} 
1 optimality and market clearing conditions to be exactly identified. In the composite, agricultural,

2 and forestry sectors, this implies that

$$
Y^{s}=A^{s}\left(\sum_{j=\{K, L, R\}} d_{j}^{s}\left(j^{s}\right)^{\rho^{s}}\right)^{1 / \rho^{s}}
$$

4 for $s=\{a, f, x\}$, where $A^{s}$ is a calibrated scaling/technology parameter, and $d_{j}^{s}, j=\{K, L, R\}$,

5 are calibrated share parameters such that $\Sigma_{j=\{K, L, R\}} d_{j}^{s}=1$ for $s=\{a, f, x\}$. The elasticity of subs-

6 titution is defined by $\sigma^{s} \equiv 1 /\left(1-\rho^{s}\right)$.

7 In the cellulosic feedstock refining and blended fuel sectors we employ nested CES func-

8 tions, which allows us to capture different elasticities of substitution between pairs of inputs. The

9 functional form specification for the cellulosic feedstock refining sector is as follows:

$$
Y^{c}=A^{c}\left(\left(\alpha^{c}\right)\left(\sum_{j=\left\{K^{c}, L^{c}\right\}} d_{j}^{c}(j)^{\rho_{K^{c} L^{c}}^{c}}\right)^{\rho^{c} / \rho_{K^{c} L^{c}}^{c}}+\left(1-\alpha^{c}\right)\left(\sum_{j=\left\{Y^{a}, Y^{f}\right\}} d_{j}^{c}(j)^{\rho_{Y^{a} a_{Y} f}^{c}}\right)^{\rho^{c} / \rho_{Y^{a}}^{c} f}\right)^{1 / \rho^{c}},
$$

11 which allows for separate elasticities of substitution for capital and labor, $\sigma_{K^{c} L^{c}}^{c}$, cellulosic feeds-

12 tock from agricultural and forestry sectors, $\sigma_{Y^{a} Y^{f}}^{c}$, and between each pair of inputs, $\sigma^{c}$. The

13 functional form for the blended fuel sector follows a similar pattern:

$$
Y_{i}^{b}=A^{b}\left(\left(\alpha^{b}\right)\left(\sum_{j=\left\{K_{i}^{b}, L_{i}^{b}\right\}} d_{j}^{b}(j)^{\rho_{K^{b} L^{b}}^{b}}\right)^{\rho^{b} / \rho_{K^{b} L^{b}}^{b}}+\left(1-\alpha^{b}\right)\left(\sum_{j=\left\{Y_{i}^{c}, Y_{i}^{o}\right\}} d_{j}^{b}(j)^{\rho_{Y^{c} Y^{o}}^{b}}\right)^{\rho^{b} / \rho_{Y^{c} Y^{o}}^{b}}\right)^{1 / \rho^{b}}
$$

15 allowing for separate elasticities of substitution for capital and labor, $\sigma_{K^{b} L^{b}}^{b}$, crude oil and cellu-

16 losic ethanol from the refining sector, $\sigma_{Y^{c} Y^{o}}^{b}$, and between each pair of inputs, $\sigma^{b}$. Elasticities of 17 substitution used in the calibration are reported in Table $1 .{ }^{9}$

\footnotetext{
${ }^{9}$ We obtained as many elasticities from the literature as we could, and for the sectors for which no data was available, we started with an elasticity of substitution of 0.50 , between Leontief and Cobb-Douglas. Robustness to this assumption is tested and reported in Table 5.
} 
The data used in the calibration and simulations are derived from different sources. We ob-

2 tain quantity and price data for Washington, Oregon, and Idaho for various sectors and summar-

3 ize their values and sources in Table 2. Differences in state-level quantities demonstrate Wash-

4 ington State's emphasis on agriculture over forestry, whereas Oregon is the opposite. Both Ida-

5 ho's forestry and agricultural sectors are smaller than Washington or Oregon. Washington State

6 employs more labor and capital in agriculture and less labor and capital in forestry than Oregon.

7 Washington State has a higher wage rate and land rental rate than Oregon or Idaho. The re-

8 mainder of the prices in the model do not vary by state.

9 In 2014, the EPA reported national production of cellulosic ethanol equal to 33 million gal-

10 lons (RFSP 2015). As state-level production is not provided, we assume that Washington State,

11 Oregon, and Idaho accounted for a share of national cellulosic ethanol production equal to their

12 respective shares of national petroleum consumption. In 2012, Washington's share of national

13 petroleum consumption was 2\% (EIA 2013d), Oregon's share was 0.9\% (EIA 2013b), and Ida-

14 ho's share was $0.4 \%$ (EIA 2013a), accounting for cellulosic ethanol production of 660,000 gal-

15 lons, 297,000 gallons, and 132,000 gallons respectively. The robustness of this anchoring point

16 for the simulation is discussed in the simulation results section.

17 In our model, we disaggregate the production of cellulosic feedstock into two sources, agri-

18 culture and forestry. Without information specifying production from each sector, we assume

19 that half the feedstock is produced by the agricultural sector (in the form of switchgrass) and half

20 from the forestry sector. ${ }^{10}$

\footnotetext{
${ }^{10}$ While switchgrass has typically been grown in areas with more summer moisture, pilot studies have concluded that irrigated switchgrass, can produce yields equal to or greater than corn silage from corn grown in the same region (Fransen 2009). Thus, the transition from existing irrigated crops to switchgrass is possible in the arid western U.S. climate, but agronomists note that a three to four year transition period is required before switchgrass can yield sufficient biomass (Fransen 2009). The static nature of our model does not allows us to consider such a transition period., but we hope to address this potentially costly transition in further research.
} 
In other regions of the country, utilizing an alternative ratio may be advisable due to differ-

2 ences in the comparative advantage of forestry and agricultural sectors. To explore this potential

3 we calibrate and test our model with agricultural to forestry feedstock ratios of $60 / 40,70 / 30$,

4 40/60, and 30/70. Using yield data from Sims et al. (2010), we calculate the amount of forest re-

5 sidues and switchgrass required to produce the postulated amount of cellulosic ethanol per

6 state. $^{11}$ To calculate the forestry land requirement, we multiply forest residues (dry tons) by the

7 ratio of state-level forestry land to state-level residue production (Gale et al. 2012; Smith 2012).

8 The agricultural land requirement is based on an estimated yield of 6 dry tons of switchgrass per

9 acre (University of Kentucky 2013). We assume capital/land and labor/land ratios are the same

10 as in state-level agriculture and forestry production.

11 Finally, the utility function is CES as well, such that $U(B, X)=\left(d_{B} B^{\rho}+d_{X} X^{\rho}\right)^{1 / \rho}-\delta E$. We

12 obtain a value for $\delta$ from the literature, utilizing Galinato and Yoder (2010), which equates the

13 disutility of pollution to $\$ 25 /$ ton of $\mathrm{CO}_{2}$. We use an emissions coefficient for blended fuel equal

14 to 0.0089 tons of $\mathrm{CO}_{2}$ /gallon (EIA 2016), and an emissions coefficient for cellulosic ethanol

15 equal to 0.0012 tons of $\mathrm{CO}_{2}$ /gallon (Wang, Wu and Huo 2007).

$16 \quad 4.2$ Simulation and calibration procedure

17 To calibrate the individual share parameters of the production functions, we use the method out-

18 lined by Howitt (1995), wherein each system of first-order conditions is solved simultaneously

19 for the unknown share and scaling parameters as a function of baseline data. As an example,

20 consider the following calibration of the forestry sector. After applying the CES functional form

21 to the forestry production function, we can write the ratio of any two first-order conditions as:

\footnotetext{
11 Sims et al. (2010) indicate a range of 110 to 270 liters per ton (1/t) for conversion from agricultural material (switchgrass) to ethanol, and a range of 125 to $300 \mathrm{l} / \mathrm{t}$ for forestry residues. We use the midpoints of each range for our conversion factor.
} 


$$
\frac{d_{i}^{f}}{d_{j}^{f}}=\frac{\left(j^{f}\right)^{\rho^{f}-1} p_{i}}{\left(i^{f}\right)^{\rho^{f}-1} p_{j}}, \text { for } i, j=K, L, R \text { where } p_{i} \text { is the price for input } i, i=K, L, R \text {. }
$$

2 Combining two of the ratio conditions and the condition that $d_{K}^{f}+d_{L}^{f}+d_{R}^{f}=1$ uniquely identi-

3 fies the share parameters. The scaling parameter $A^{f}$ is recovered from the production function:

$$
A^{f}=\frac{Y^{f}}{\left(d_{K}^{f}\left(K^{f}\right)^{\rho^{f}}+d_{L}^{f}\left(L^{f}\right)^{\rho^{f}}+d_{R}^{f}\left(R^{f}\right)^{\rho^{f}}\right)^{1 / \rho^{f}}} .
$$

To calibrate $d_{i}^{f}, i=K, L, R$ and $A^{f}$, we require data for the elasticity of substitution, $6 \quad \sigma^{f}=1 /\left(1-\rho^{f}\right)$, input quantities, $K^{f}, L^{f}$, and $R^{f}$, and the output quantity, $Y^{f}$, which can be

7 found in Table 1 and Table 2. Calibration of the remaining sectors is conducted in a similar man8 ner.

9 After our calibration, we conduct a numerical simulation to determine the optimal taxes and 10 subsidies in both the revenue-unconstrained (Pigouvian) case and the revenue-constrained case 11 under the model. Deriving the optimal taxes and subsidies allows us to analyze changes in social 12 welfare, blended fuel consumption and cellulosic ethanol production.

13 Without an analytical expression, we utilize numerical optimization to solve for the optimal 14 tax rates. Specifically, we form a system of 27 equations in 27 unknowns, consisting of the first15 order conditions from each sector. We then specify a grid for the optimal revenue-unconstrained 16 (Pigouvian) tax, ranging from -1 to +1 in increments of 0.05 , for both crude oil and cellulosic 17 ethanol taxes. At each point in the two dimensional grid, the entire system of 27 equations is re18 solved, and the corresponding social welfare value is calculated at each point. We define the lo19 cally optimal tax as the point that is associated with the highest social welfare. Cellulosic ethanol 20 and blended fuel production are calculated at this point as well.

21 The numerical simulation for the revenue-constrained $(T=0)$ case proceeds in a similar fa- 
1 shion, with the exception of the grid specification. In this case, we specify a grid for cellulosic

2 fuel ranging from -2 to +2 , and we specify a crude oil tax based on the value of the cellulosic

3 fuel tax derived from the revenue-neutrality expression which is:

$4 \quad(22)$

$$
\tau^{c} Y^{c}+\tau^{o} Y^{o}=0 \Rightarrow \tau^{o}=-\tau^{c}\left(Y^{c} / Y^{o}\right)
$$

5 The entire set of 27 model equations is re-solved at every iteration, and the revenue-neutral tax

6 combination associated with the highest social welfare calculation is chosen as the local opti-

7 mum.

\section{5. Simulation results}

9 Table 3 summarizes the simulation results that calculate the optimal taxes, fuel production and

10 social welfare changes. The revenue-unconstrained taxes for crude oil vary by state, ranging

11 from a low of $\$ 0.35 /$ gallon in Idaho to a high of $\$ 0.92 /$ gallon in Oregon. All taxes are higher

12 than the Pigouvian rate, suggesting a positive addition to the tax rate to account for the waiver

13 revenue effect. Note that the marginal damage, $\delta$, and the emissions coefficients $e^{c}$ and $e^{o}$ do

14 not vary across states. The differences in simulated tax rates are mainly due to the marginal im-

15 pact of taxes on endogenous variables, which vary by state.

16 Revenue-unconstrained taxes for cellulosic ethanol are lower than crude-oil taxes, reflecting

17 their lower emissions coefficient. They vary by state as well, from $\$ 0.12$ gallon in Idaho to

$18 \$ 0.51 /$ gallon in Washington. Our estimates are comparable to the results simulated by Galinato

19 and Yoder (2010) where they derive an output tax of $\$ 0.198$ for cellulosic ethanol for the entire

20 United States. Interestingly, the ordering of taxes across states is not consistent between crude oil

21 and cellulosic ethanol taxes. The differences can be attributed to the sensitivity of the blended

22 fuel prices and waiver revenues to taxes in each state. 
Revenue-constrained taxes, with revenues set to zero, are smaller for both crude oil and cel-

2 lulosic ethanol. Crude oil taxes are small, ranging from $\$ 0.00006 /$ gallon to $\$ 0.0005 /$ gallon. The

3 revenue-constrained taxes for cellulosic ethanol are actually subsidies. In Washington, the subsi-

$4 \mathrm{dy}$ is $\$ 0.41 /$ gallon, and in Idaho, the subsidy is $\$ 1.28 /$ gallon. The large difference in magnitude

5 between crude oil and cellulosic ethanol taxes/subsidies is due to the low input ratio between cel-

6 lulosic ethanol and crude oil. Only a small amount of tax on crude oil is needed to subsidize cel-

7 lulosic ethanol production. Aggregated to the state-level, this equates to a total tax bill between

$8 \quad 0.3402$ million dollars for Washington and 0.565 million dollars for Idaho collected from crude

9 oil and used to subsidize cellulosic ethanol. The reason why revenues are not as large is because

10 cellulosic ethanol itself has a positive emission coefficient which is $14 \%$ of the crude oil coeffi-

11 cient (Wang, Wu and Huo 2007).

12 Blended fuel and cellulosic ethanol production are affected when the taxes are imposed. In

13 the revenue-unconstrained case, blended fuel and cellulosic ethanol both decrease from about $7 \%$

14 to $15 \%$ and from $1 \%$ to $15 \%$, respectively, depending on the state. In the revenue-constrained

15 case, crude oil use drops a negligible amount, but cellulosic ethanol increases from $28.5 \%$ to

$16238.4 \%$.

17 In either tax scenario, total changes to welfare are minor. The maximum welfare change in

18 the revenue-unconstrained case is just $0.49 \%$, while the change in the revenue-constrained case

19 is practically zero. Constraining tax revenues have an impact on welfare, but that impact is neg-

20 ligible. The results are similar to those derived by Galinato and Yoder (2010) where they show

21 that imposing a revenue-neutral tax only increases welfare by $1 \%$ of the total increase in welfare

22 relative to the revenue unconstrained case.

23 The RFS policy variables perfectly substitute for the taxes as shown in equations (6). An in-

24 crease in the cellulosic ethanol subsidy has the same effect as an increase in the cellulosic waiver 
credit price, and an increase in the crude oil tax has a similar effect to increasing the waiver price

2 multiplied by the cellulosic percentage standard. Thus, as the input ratio requirement increases

3 based on the RFS schedule, the optimal crude oil tax would decline. If the tax revenue target is

4 fixed at zero, the optimal cellulosic ethanol subsidy will also decrease accordingly. On the other

5 hand, if the waiver price increases, the optimal cellulosic ethanol subsidy will fall, as will the

6 crude oil tax to ensure revenue neutrality. In this case, the waiver price acts like a tax on crude 7 oil.

\section{$8 \quad 5.1$ Robustness}

9 In Table 4, we explore the robustness of the assumption that the agricultural and forestry sectors

10 each produce $50 \%$ of total cellulosic feedstock at the baseline for Washington State. We re-run

11 the calibration and simulation under four alternative agricultural to forestry feedstock ratios.

12 In general, the qualitative comparison across the states remain the same but we also learn

13 how differences in the opportunity cost of the feedstocks affects taxes, production and welfare.

14 Increasing the percentage of agricultural feedstock results in higher optimal crude oil taxes and

15 lower cellulosic ethanol taxes for both revenue-unconstrained and revenue-neutral cases. Further,

16 with a higher (lower) percentage of agricultural feedstock, the decline in fuel production as a re-

17 sult of tax imposition is subdued (exacerbated) in the revenue-unconstrained case. In the reve-

18 nue-neutral case, the decline in crude oil is smaller (higher) with more (less) agricultural feeds-

19 tock, and the increase in cellulosic ethanol is larger (smaller). In both tax scenarios, the percen-

20 tage change in social welfare is smaller (larger) with more (less) agricultural feedstock.

21 The relationship between agricultural feedstock use, taxes, blended fuel production and wel-

22 fare is tied to the impact on the composite good sector. When more agricultural feedstock is used

23 for cellulosic feedstock relative to forestry feedstock at the baseline, composite commodity con- 
1 sumption by the consumer decreases due to the higher relative price of agricultural goods, which

2 are now being diverted to fuel production. This prompts substitution to blended fuel consump-

3 tion, increasing demand for blended fuel and blended fuel inputs. Welfare decreases due to the

4 decline in composite commodity consumption as the higher value agricultural feedstock is di-

5 verted to fuel. Finally, because of an increase in waiver expenditures, the marginal waiver effect

6 is exacerbated, which necessitates an increase in the environmental tax for crude oil.

7 Another robustness check is conducted for the elasticity of substitution parameters, which we

8 lack for several sectors. In general, we set elasticities to allow for either near perfect substituta-

9 bility or near perfect complementarity. Model results are very robust to the pairs of inputs for

10 which we have designated near perfect substitutability (crude oil and cellulosic ethanol, cellulos-

11 ic material from forestry and agricultural sectors). Table 5 displays the results of a robustness

12 check on the input pairs assumed to have an elasticity of 0.50 for Washington State. We re-run

13 the simulation assuming elasticities of 0.01 (approaching Leontief) and 0.99 (approaching Cobb-

14 Douglas) for each sector/input pair. In general, we find very little change to the optimal tax rates

15 and associated welfare measures. The average change in optimal taxes across all sectors is less

16 than two percent.

17 Table 6 presents results illustrating the model's robustness to changes in the initial cellulosic

18 ethanol production level. In general, the qualitative comparison between the three states remain

19 the same. The intuition gained in analyzing the robustness check in Table 4 is applicable here as

20 well. The first column reprints the baseline results from Table 3 for Washington State, and the

21 next two columns reproduce those results with one percentage increases in the calibrated level of

22 cellulosic ethanol production. As more feedstock is diverted to the production of fuel, composite

23 commodity consumption declines which reduces consumer surplus for the good, and the increase

24 in consumer surplus from an increase in fuel supply is insufficient to make up the welfare deficit. 
1 Furthermore, crude oil taxes increase, cellulosic ethanol taxes decrease, the decline in fuel pro-

2 duction is slightly lower, and welfare decreases relative to the base case.

\section{6. Conclusion}

4 This article derives the optimal integrated tax-subsidy policy that reduces GHG emissions given

5 the existing policies under the RFS to measure welfare effects and cellulosic fuel production. We

6 develop a general equilibrium model that incorporates six sectors which includes two feedstock

7 sectors (agriculture and forestry), a cellulosic refining sector, a blended fuel sector, a composite

8 good producing sector and a consumption sector of final goods. A welfare maximizing govern-

9 ment selects taxes on the use of crude oil and cellulosic ethanol.

10 We find that if a revenue-unconstrained tax is imposed, the crude oil and cellulosic ethanol

11 taxes are higher than the marginal damages based on the emissions coefficients of both inputs. A

12 premium is added to the pollution tax rate to internalize the added distortion created by the exis13 tence of the waiver credit.

14 A revenue-neutral tax subsidy scheme leads to a positive tax rate for crude oil with a small

15 magnitude ranging from $\$ 0.00006 /$ gallon to $\$ 0.0005 /$ gallon while cellulosic ethanol is subsidized

16 at a rate of $\$ 0.41 /$ gallon to $\$ 1.28 /$ gallon. The large difference in magnitude is due to the input

17 ratio between cellulosic ethanol and crude oil which implies only a small amount of tax on crude

18 oil is needed to subsidize cellulosic ethanol production.

19 The tax/subsidy scheme can substitute perfectly for the two jointly-implemented RFS poli-

20 cies, the cellulosic percentage standard and the waiver credit policy. This relationship implies

21 that individual states could augment the impact of the RFS policy through an appropriately cho-

22 sen integrated tax/subsidy. As the cellulosic percentage standard increases over time in accor-

23 dance with the RFS legislation, both the optimal cellulosic ethanol subsidy and crude oil tax will 
decline.

2 Our robustness check on varying the ratio of agricultural and forestry feedstock used in cellu-

3 losic ethanol production illustrates an important point that generalizes our analysis to regions

4 with varying levels of agricultural and forestry inputs. Namely, the opportunity cost of a poten-

5 tial cellulosic ethanol feedstock source matters a great deal when assessing the social welfare

6 consequences of implementing a revenue-neutral carbon tax. Our model predicts that the welfare

7 gain will be lower if a regional economy is required to use a cellulosic ethanol feedstock source

8 with a high opportunity cost.

9 The welfare effects of a revenue-neutral tax-subsidy scheme are small compared to a reve-

10 nue-neutral pollution tax that reduces an existing distortionary tax such as a sales tax or income

11 tax. Skolrud and Galinato (2015) show that increasing a tax on blended fuel and reducing a sales

12 tax in Washington or income tax in Oregon increases social welfare by $19 \%$ to $20 \%$ while the

13 integrated tax-subsidy scheme yields less than a $1 \%$ increase in welfare. However, cellulosic fuel

14 production only increases by about $1 \%$ in a revenue-neutral tax while the integrated tax subsidy

15 increases cellulosic fuel production by $28 \%$ to $238 \%$. The results make intuitive sense since the

16 integrated tax-subsidy framework only affects the energy sector while a revenue-neutral pollu-

17 tion tax would affect a larger share of the economy. Thus, a policymaker who is more concerned

18 about a growing cellulosic fuel industry would opt to impose an integrated tax-subsidy policy

19 within the energy industry as opposed to a revenue-neutral tax affecting multiple sectors in the 20 economy. 


\section{References}

Amdur, D., B. Rabe and C. Borick. 2014. Public Views on a Carbon Tax Depend on the Proposed Use of Revenue. Issues in Energy and Environmental Policy (13). Available at: http://closup.umich.edu/files/ieep-nsee-2014-spring-carbon-tax.pdf

Banks J., Blundell, R., and A. Lewbel. 1997. Quadratic Engel Curves and Consumer Demand. The Review of Economics and Statistics 79: 527-539.

BLS (U.S. Bureau of Labor Statistics). 2013a. May 2012 State Occupational Employment and Wage Estimates: Washington State. Available at: http://www.bls.gov/oes/current/oes_wa.htm\#45-0000 (accessed September 2013).

—. 2013b. May 2012 State Occupational Employment and Wage Estimates: Idaho. Available at:

http://www.bls.gov/oes/current/oes_id.htm\#45-0000 (accessed September 2013).

—. 2013b. May 2012 State Occupational Employment and Wage Estimates: Oregon. Available at:

http://www.bls.gov/oes/current/oes_or.htm\#45-0000 (accessed September 2013).

British Columbia Ministry of Small Business and Revenue. 2008. British Columbia Carbon Tax Update. British Columbia Government. Available at: http://www.sbr.gov.bc.ca/documents_library/notices/BC_Carbon_Tax_Update.pdf

Daniels, J. M. 2010. Assessing the Lumber Manufacturing Sector in Western Washington. Forest Policy and Economics 12: 129-135.

EIA (U.S. Energy Information Administration). 2013a. Idaho Profile and Energy Estimates: Profile Analysis. Available at: http://www.eia.gov/state/?sid=ID (accessed December 2013).

—. 2013b. Oregon Profile and Energy Estimates: Profile Analysis. Available at: http://www.eia.gov/state/?sid=OR (accessed December 2013). 
1 - 2013c. Spot Prices for Crude Oil and Petroleum Products. Available at:

2 http://www.eia.gov/dnav/pet/pet_pri_spt_s1_d.htm (accessed September 2013).

3 - 2013d. Washington State Profile and Energy Estimates: Profile Analysis. Available at:

4 http://www.eia.gov/state/?sid=WA (accessed December 2013).

5 - 2013e. West Coast Less California Gasoline and Diesel Retail Prices. Available at:

6 http://www.eia.gov/dnav/pet/pet_pri_gnd_dcus_r5xca_a.htm (accessed September 2013).

7 - 2016. Carbon Dioxide Emissions Coefficients. Available at:

8 https://www.eia.gov/environment/emissions/co2_vol_mass.cfm (accessed March 2016).

9 EPA (U.S. Environmental Protection Agency). 2013. "RFS2 EMTS Informational Data, 2012

10 RFS2 Data.” Available at: http://www.epa.gov/otaq/fuels/rfsdata/2012emts.htm

11 . 2016. Final Renewable Fuel Standards for 2014, 2015 and 2016, and the Biomass-Based

12 Diesel Volume for 2017. Available at https://www.epa.gov/renewable-fuel-standard-

13 program/final-renewable-fuel-standards-2014-2015-and-2016-and-biomass-based (ac-

$14 \quad$ cessed March 2016).

15 ERS (USDA Economic Research Service). 2014. National Tables, 1948-2011, Tractor Rental

16 Rate. Available at: http://www.ers.usda.gov/data-products/agricultural-productivity-in-

17 the-us.aspx (accessed February 2014).

18 Fransen, S. 2009. Agronomics of Switchgrass for Biofuel in the West. Proceedings of the 2009

19 Western Alfalfa \& Forage Conference.

20 Gale, C. B., Keegan III, C. E., Berg, E., Daniels, J., Christensen, G. A., Sorenson, C. B., Morgan, 21 T. A., and P. Polzin. 2012. Oregon's Forest Products Industry and Timber Harvest, 2008:

22 Industry Trends and Impacts of the Great Recession through 2010. USDA General Tech23 nical Report PNW-GTR-868. 
1 Galinato, G. I. and J. K. Yoder. 2010. An Integrated Tax-Subsidy Policy for Carbon Emission Reduction. Resource and Energy Economics 32: 310-326.

3 Governors' Biofuel Coalition (GBC). 2011. Cellulosic Ethanol Won't Reach First-Generation 4 Price Until 2020 - Study. Available at:

5 http://www.governorsbiofuelscoalition.org/?p=679 (accessed September 2013).

6 Government Printing Office (GPO). 2011. Code of Federal Regulations, Title 40, Part 80.1456.

$7 \quad$ Available at:

8 http://www.gpo.gov/fdsys/browse/collectionCfr.action?collectionCode=CFR

9 Greene, D. L., Patterson, P. D., Singh, M., and J. Li. 2005. Feebates, Rebates and Gas-Guzzler

10 Taxes: A Study of Incentives for Increased Fuel Economy. Energy Policy. 33: 757-775.

11 Hammar, H., and S. Jagers. 2007. What is a Fair CO2 Tax Increase? On Fair Emission Reduc-

12 tions in the Transport Sector. Ecological Economics 6: 377-387.

13 Helfand, G.E., 1991. Standards versus Standards: The Effects of Different Pollution Restrictions.

$14 \quad$ The American Economic Review 81: 622-634.

15 Howitt, R. E. 1995. A Calibration Method for Agricultural Economic Production Models.

$16 \quad$ Journal of Agricultural Economics 46: 147-159.

17 International Energy Agency (IEA). 2002. Energy Policies of IEA Countries: Denmark Review

18 (PDF). Head of Publications Service, OECD/IEA 2, rue André-Pascal, 75775 Paris Ce-

19 dex 16, France.

20 Johnson, K. C. 2006. Feebates: An Effective Regulatory Instrument for Cost-Constrained Envi-

21 ronmental Policy. Energy Policy 34: 3965-3976.

22 Kopczuk, W. 2003. A Note on Optimal Taxation in the Presence of Externalities. Economics Let$23 \quad$ ters $80: 81-86$. 
1 Metcalf, G.E. 2009. Designing a Carbon Tax to Reduce U.S. Greenhouse Gas Emissions. Review of Environmental Economics and Policy 3: 63-83.

3 NASS (USDA National Agricultural Statistics Service). 2013a. Quick Stats: Rent, Cash, Crop4 land-Expense. Available at: http://quickstats.nass.usda.gov/results/95303089-CE933EED-9B56-68C096A8B8CB (accessed September 2013).

6 - 2013b. Quick Stats: Tractors-Inventory. Available at:

7 http://quickstats.nass.usda.gov/results/3EE349F8-6DF1-30C4-BCA0-C67A886F25A8

$8 \quad$ (accessed September 2013).

9 - 2013c. Quick Stats: Area Cropland, Harvested. Available at:

10 http://quickstats.nass.usda.gov/results/93F20082-8A27-3E48-9524-37A2749EE556 (ac-

$11 \quad$ cessed September 2013).

12 . 2013d. Crop Values: 2012 Summary. Available at:

13 http://usda.mannlib.cornell.edu/usda/nass/CropValuSu//2010s/2012/CropValuSu-02-1614 2012.pdf (accessed September 2013).

15 New York Times, 2009. Europe's Way of Encouraging Solar Power Arrives in the U.S. Available at: http://www.nytimes.com/2009/03/13/business/energy-environment/13solar.html.

17 Parry, I. 1998. A Second-Best Analysis of Environmental Subsidies. International Tax and Public Finance 5: 153-170.

19 Renewable Fuel Standard Program (RFSP): Standards for 2014, 2015, and 2016 and BiomassBased Diesel Volume for 2017, 80 Fed. Reg. No. 111 (Jun. 10, 2015) (amending 40 CFR

22 Sandmo, A., 1975. Optimal Taxation in the presence of externalities. Swedish Journal of Economics 77: 86-98. 
1 Simmons, E. A., S. W. Hayes, T. A. Morgan, C. E. Keegan III, C. Witt. 2014. Idaho’s Forest Products Industry and Timber Harvest 2011 with Trends Through 2013. Resource. Bulletin. RMRS-RB-19. Fort Collins, CO: U.S. Department of Agriculture, Forest Service, Rocky Mountain Research Station.

Sims, R. E. H., W. Mabee, J. N. Saddler, and M. Taylor. 2010. An Overview of Second Generation Biofuel Technologies. Bioresource Technology 101: 1570-1580.

Skolrud, T., G. Galinato, S. Galinato, C. R. Shumway, and J. Yoder. 2014. The Role of Market Structure and Federal Renewable Fuel Standards in the Growth of the Cellulosic Biofuel Sector. Working Paper 2014-2.

Skolrud, T. and G. Galinato. 2015. Welfare Implications of the Renewable Fuel Standards with a Revenue-Neutral Tax. Working Paper 2015-18.

Smith, D. 2012. Washington Mill Survey 2010: Series Report \#21. Washington State Department of Natural Resources. Available at: http://www.dnr.wa.gov/Publications/obe_econ_rprt_millsurv_2010.pdf (accessed September 2013).

Tol, R. S. J. 2005. The Marginal Damage Costs of Carbon Dioxide Emissions: An Assessment of the Uncertainties. Energy Policy 33: 2064-2074.

University of Kentucky. 2013. Switchgrass for Bioenergy. University of Kentucky College of Agriculture Cooperative Extension Service. Available at: https://www.uky.edu/Ag/CDBREC/introsheets/switchgrass.pdf (accessed September 2013). 
1 Vourc'h, A. and M. Jimenez. 2000. Enhancing Environmentally Sustainable Growth in Finland. Economics Department Working Papers No. 229. Available at: http://www.oecd-ilibrary.org/economics/enhancing-environmentally-sustainable-growthin-finland_370821866730

Wang, M., M. Wu, and H. Huo. 2007. Life-Cycle Energy and Greenhouse Gas Emission Impacts of Different Corn Ethanol Plant Types. Environmental Research Letters 2: 1-13.

Washington Research Council (WRC). 2012. The Economic Contribution of Washington State's Petroleum Refining Industry in 2011. Economic Profile. Available at: https://researchcouncil.files.wordpress.com/2013/08/2012refineryreportfinal040913.pdf (accessed March 2015).

Washington State: Office of the Attorney General. Washington 2007-2008 Gas Price Study. Available at: http://www.atg.wa.gov/washington-2007-2008-gas-price-study (accessed March 2016).

Yi, F., Mérel, P., Lee, J., Farzin, Y. H., and J. Six. 2013. Switchgrass in California: where, and at what price? Global Change Biology: Bioenergy, 1-15. doi: 10.1111/gcbb.12075.

Yoder, J., C. R. Shumway, P. Wandschneider, D. Young, H. Chouinard, A. Espinola-Arredondo, S. Galinato, C. Frear, D. Holland, E. Jessup, J. LaFrance, K. Lyons, M. McCullough, K. Painter and L. Stodick. 2010. "Biofuel economics and policy for Washington State." Washington State Univ. Agr. Res. Center Res. Bul. XB1047E. 1 Aug. 2013. http://cru.cahe.wsu.edu/CEPublications/XB1047E/XB1047E.pdf. 


\section{Tables and figures}

Table 1-Elasticities of Substitution

\begin{tabular}{lrl}
\hline \hline Sector & Elasticity & Source \\
\hline Agricultural sector $^{\mathrm{a}}$ & 0.21 & Yi et al. (2014) \\
Forestry sector $^{\mathrm{b}}$ & 0.46 & Daniels (2010) \\
Cellulosic refining sector & & \\
$\quad$ Total & 0.50 & Assumption \\
$\quad$ Labor/capital & 0.50 & Assumption \\
$\quad$ Agricultural cellulose/forestry cellulose & $\rightarrow \infty$ & Assumption \\
Blended fuel sector & & \\
$\quad$ Total & 0.50 & Assumption \\
$\quad$ Labor/capital & 0.50 & Assumption \\
$\quad$ Crude oil/cellulosic ethanol & $\rightarrow \infty$ & Assumption \\
Composite good sector & 0.50 & Assumption \\
Consumer's utility function & 0.1068 & Banks et al. (1997)
\end{tabular}

${ }^{\mathrm{a}} \mathrm{We}$ use estimates from switchgrass production for the agricultural sector.

4

${ }^{\mathrm{b}}$ The elasticity is an average of three different estimated elasticities between capital and labor, labor and logs, and capital and logs. 
Table 2-Parameter Values

\begin{tabular}{|c|c|c|c|c|c|}
\hline \multirow[t]{2}{*}{ Parameters } & \multicolumn{3}{|c|}{ State } & \multirow[t]{2}{*}{ Units } & \multirow[t]{2}{*}{ Source } \\
\hline & WA & OR & ID & & \\
\hline \multicolumn{6}{|l|}{ Inputs: } \\
\hline Agricultural labor ${ }^{\mathrm{a}}$ & 1.16 & 0.34 & 0.10 & Full-time laborers ${ }^{\mathrm{g}}$ & BLS (2013a; 2013b; 2013c) \\
\hline Agricultural capital $^{\mathrm{b}}$ & 3.79 & 1.56 & 0.80 & Tractors/equipment & NASS $(2013 b)$ \\
\hline Agricultural resources & 1,096 & 493.10 & 219.16 & Acres & NASS $(2013 c)$ \\
\hline Forestry labor ${ }^{c}$ & 3.17 & 1.87 & 0.72 & Full-time laborers & BLS (2013a; 2013b; 2013c) \\
\hline Forestry capital $^{\mathrm{d}}$ & 52.82 & 29.67 & 50.91 & Capital units ${ }^{\mathrm{h}}$ & Smith (2012), Simmons et al. (2014), Gale et al. (2012) \\
\hline Forestry resources & 17,257 & 11,840 & 14,095 & Acres & Smith (2012), Simmons et al. (2014), Gale et al. (2012) \\
\hline Cellulosic refining labor & 22.60 & 10.17 & 4.52 & Full-time laborers & BLS (2013a; 2013b; 2013c) \\
\hline Cellulosic refining capital & 342.64 & 154.19 & 68.53 & Capital units & WRC (2012) \\
\hline Fuel blending labor ${ }^{\mathrm{e}}$ & 1130 & 508 & 226 & Full-time laborers & BLS (2013a; 2013b; 2013c) \\
\hline Fuel blending capital ${ }^{\mathrm{f}}$ & 17,132 & 7,709 & 3,426 & Capital units & WRC (2012) \\
\hline Crude oil & 5.67 & 2.55 & 1.13 & Gallons (bil.) & EIA (2013d; 2013b; 2013a) \\
\hline Composite good labor & 15,035 & 12,098 & 4,839 & Full-time laborers & BLS (2013a; 2013b; 2013c) \\
\hline Composite good capital & 174,157 & 159,495 & 130,830 & Capital units & $\begin{array}{l}\text { NASS (2013b), Smith (2012), Simmons et al. (2014), Gale et al. } \\
(2012)\end{array}$ \\
\hline Composite good resources & 27.65 & 36.57 & 25.87 & Acres (mil.) & $\begin{array}{l}\text { NASS (2013c), Smith (2012), Simmons et al. (2014), Gale et al. } \\
(2012)\end{array}$ \\
\hline \multicolumn{6}{|r|}{ (2) } \\
\hline Cellulosic feedstock, agriculture ${ }^{\mathrm{i}}$ & 6,575 & 2,959 & 1,314 & Tons & Sims et al. (2010), EIA (2013d; 2013b; 2013a) \\
\hline Cellulosic feedstock, forestry ${ }^{i}$ & 5,879 & 2,645 & 1,175 & Tons & Sims et al. (2010), EIA (2013d; 2013b; 2013a) \\
\hline Cellulosic ethanol $^{\mathrm{j}}$ & 660 & 297 & 132 & Gallons (th.) & RFSP (2015), EIA (2013d; 2013b; 2013a) \\
\hline Blended fuel & 2.60 & 1.17 & 0.52 & Gallons (bil.) & EIA $(2013 d ; 2013 b ; 2013 a)$ \\
\hline Composite good ${ }^{\mathrm{k}}$ & 11.98 & 8.34 & 4.97 & \$ (bil.) & $\begin{array}{l}\text { NASS (2013d), Smith (2012), Simmons et al. (2014), Gale et al. } \\
\text { (2012) }\end{array}$ \\
\hline \multicolumn{6}{|r|}{ 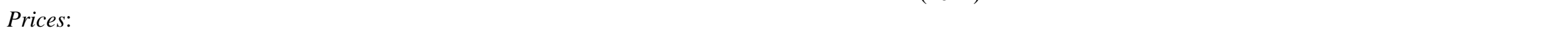 } \\
\hline Wage rate & 36,296 & 33,596 & 32,907 & \$/year & BLS (2013a; 2013b; 2013c) \\
\hline Rental rate of capital ${ }^{1}$ & 8,680 & 8,680 & 8,680 & \$/year & ERS (2014) \\
\hline Land resource price & 215 & 130 & 143 & $\$ /$ acre & NASS (2013a) \\
\hline Cellulosic feedstock, agriculture & 65 & 65 & 65 & $\$ /$ dry ton & U. Kentucky (2013) \\
\hline Cellulosic feedstock, forestry & 52.27 & 52.27 & 52.27 & $\$ /$ dry ton & Gale et al. (2012) \\
\hline Cellulosic ethanol & 2.35 & 2.35 & 2.35 & \$/gallon & GBC (2011) \\
\hline Crude oil & 2.24 & 2.24 & 2.24 & \$/gallon & EIA $(2013 c)$ \\
\hline Final blended fuel ${ }^{\mathrm{m}}$ & 3.76 & 3.76 & 3.76 & \$/gallon & EIA $(2013 e)$ \\
\hline
\end{tabular}

${ }^{a}$ Consists of agricultural inspectors, graders and sorters of agricultural products, agricultural equipment operators, and general farmworkers.

${ }^{\mathrm{b}}$ Agricultural capital is computed as an average of the amount of different types of agricultural equipment (tractors) used in Washington State in 2012.

${ }^{\mathrm{c}}$ Labor input in the forestry sector consists of forest and conservation workers, fallers, logging equipment operators, and log graders and scalers.

${ }^{\mathrm{d}}$ Annual operating cost for sawmills multiplied by the number of sawmills in each state, expressed in capital units. ${ }^{\mathrm{h}}$

${ }^{\mathrm{e}}$ Labor for the blended fuel sector includes categories for petroleum pump system operators, refinery operators and gaugers. 
${ }^{\mathrm{f}}$ Total 2012 non-labor capital expenditures, expressed in capital units. ${ }^{\mathrm{h}}$

${ }^{\mathrm{g}}$ Full-time laborers are those that are employed 40/hrs/wk. for one year.

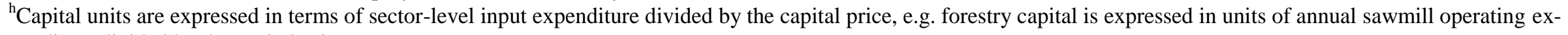
penditure divided by the capital price.

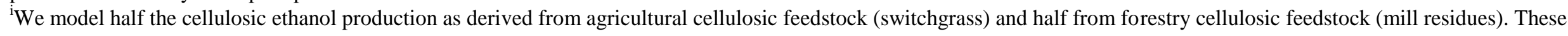
values represent the necessary amount of feedstock required to produce those levels in accordance with the conversion factors in Sims et al. (2010).

${ }^{\mathrm{j}}$ Equal to the 2014 RFS mandated level of cellulosic ethanol multiplied by each state's share of national petroleum consumption.

${ }^{\mathrm{k}}$ The sum of total value from agriculture and forestry sectors by state.

${ }^{1}$ Annual tractor rental rate.

${ }^{\mathrm{m}}$ The final blended fuel price is the 2012 average retail gasoline price for the Western United States less California. 
Table 3-Optimal Taxes, Changes in Fuel Production and Welfare

\begin{tabular}{|c|c|c|c|}
\hline & \multicolumn{3}{|c|}{ State } \\
\hline & WA & OR & ID \\
\hline \multicolumn{4}{|l|}{ Optimal taxes (\$/gallon) } \\
\hline \multicolumn{4}{|l|}{ Revenue unconstrained } \\
\hline Crude oil & $\$ 0.74$ & $\$ 0.92$ & $\$ 0.35$ \\
\hline Cellulosic ethanol & $\$ 0.51$ & $\$ 0.23$ & $\$ 0.12$ \\
\hline \multicolumn{4}{|l|}{ Revenue-neutral $(T=0)$} \\
\hline Crude oil & $\$ 0.00006$ & $\$ 0.00012$ & $\$ 0.00050$ \\
\hline Cellulosic ethanol & $-\$ 0.41$ & $-\$ 0.68$ & $-\$ 1.28$ \\
\hline \multicolumn{4}{|c|}{ Fuel production (\% change) } \\
\hline \multicolumn{4}{|l|}{ Revenue unconstrained } \\
\hline Blended fuel & $-12.5 \%$ & $-15.1 \%$ & $-6.9 \%$ \\
\hline Cellulosic ethanol & $-15.4 \%$ & $-14.2 \%$ & $-0.8 \%$ \\
\hline \multicolumn{4}{|l|}{ Revenue-neutral $(T=0)$} \\
\hline Crude oil & $-0.0007 \%$ & $-0.0017 \%$ & $-0.0087 \%$ \\
\hline Cellulosic ethanol & $28.5 \%$ & $59.8 \%$ & $238.4 \%$ \\
\hline \multicolumn{4}{|l|}{ Welfare (\% change) } \\
\hline Revenue unconstrained & $0.29 \%$ & $0.49 \%$ & $0.13 \%$ \\
\hline Revenue-neutral $(T=0)$ & $0.00006 \%$ & $0.00020 \%$ & $0.0010 \%$ \\
\hline
\end{tabular}


Table 4-Tax, Fuel Production, and Welfare Changes for Varying Ag/Forestry Feedstock Input Ratios: Washington State ${ }^{a}$

\begin{tabular}{|c|c|c|c|c|c|}
\hline & \multicolumn{5}{|c|}{ Ag. feedstock to forestry feedstock ratio } \\
\hline & $50-50$ & $60-40$ & $70-30$ & $40-60$ & $30-70$ \\
\hline \multicolumn{6}{|l|}{ Optimal taxes (\$/gallon) } \\
\hline \multicolumn{6}{|l|}{ Revenue unconstrained } \\
\hline Crude oil & $\$ 0.74$ & $\$ 0.76$ & $\$ 0.81$ & $\$ 0.73$ & $\$ 0.69$ \\
\hline Cellulosic ethanol & $\$ 0.51$ & $\$ 0.51$ & $\$ 0.47$ & $\$ 0.51$ & $\$ 0.52$ \\
\hline \multicolumn{6}{|l|}{ Revenue-neutral $(T=0)$} \\
\hline Crude oil & $\$ 0.00006$ & $\$ 0.00006$ & $\$ 0.00007$ & $\$ 0.00006$ & $\$ 0.00006$ \\
\hline Cellulosic ethanol & $-\$ 0.41$ & $-\$ 0.41$ & $-\$ 0.42$ & $-\$ 0.41$ & $-\$ 0.41$ \\
\hline \multicolumn{6}{|c|}{ Fuel production (\% change) } \\
\hline \multicolumn{6}{|c|}{ Revenue unconstrained } \\
\hline Blended fuel & $-12.5 \%$ & $-11.8 \%$ & $-10.9 \%$ & $-13.8 \%$ & $-14.5 \%$ \\
\hline Cellulosic ethanol & $-15.4 \%$ & $-14.9 \%$ & $-13.2 \%$ & $-16.0 \%$ & $-17.7 \%$ \\
\hline \multicolumn{6}{|l|}{ Revenue-neutral $(T=0)$} \\
\hline Crude oil & $-0.0007 \%$ & $-0.0007 \%$ & $-0.0005 \%$ & $-0.0007 \%$ & $-0.0008 \%$ \\
\hline Cellulosic ethanol & $28.5 \%$ & $29.1 \%$ & $30.5 \%$ & $28.6 \%$ & $27.0 \%$ \\
\hline \multicolumn{6}{|l|}{ Welfare (\% change) } \\
\hline Revenue unconstrained & $0.29 \%$ & $0.28 \%$ & $0.24 \%$ & $0.33 \%$ & $0.37 \%$ \\
\hline Revenue-neutral $(T=0)$ & $0.00006 \%$ & $0.00006 \%$ & $0.00005 \%$ & $0.00006 \%$ & $0.00006 \%$ \\
\hline
\end{tabular}

${ }^{\mathrm{a}}$ Results for Oregon and Idaho exhibited identical patterns of change from the baseline with similar magnitudes. The results are available from the author by request. 
Table 5-Elasticity of Substitution Robustness: Washington State ${ }^{a}$

\begin{tabular}{|c|c|c|c|c|c|c|c|c|}
\hline \multirow{3}{*}{ Sector } & \multicolumn{4}{|c|}{$\sigma=0.01$} & \multicolumn{4}{|c|}{$\sigma=0.99$} \\
\hline & \multicolumn{2}{|c|}{$\begin{array}{c}\text { Revenue } \\
\text { unconstrained }\end{array}$} & \multicolumn{2}{|c|}{$\begin{array}{l}\text { Revenue constrained } \\
\qquad(T=0)\end{array}$} & \multicolumn{2}{|c|}{$\begin{array}{c}\text { Revenue } \\
\text { unconstrained }\end{array}$} & \multicolumn{2}{|c|}{ Revenue constrained $(T=0)$} \\
\hline & $\tilde{\tau}^{o}$ & $\tilde{\tau}^{c}$ & $\hat{\tau}^{o}$ & $\hat{\tau}^{c}$ & $\tilde{\tau}^{o}$ & $\tilde{\tau}^{c}$ & $\hat{\tau}^{o}$ & $\hat{\tau}^{c}$ \\
\hline Cellulosic refining sector & & & & & & & & \\
\hline Total & $\begin{array}{r}0.7401 \\
(0.0001)\end{array}$ & $\begin{array}{r}0.5105 \\
(0.0005)\end{array}$ & $\begin{array}{r}0.0000639 \\
(0.0000039)\end{array}$ & $\begin{array}{r}-0.4103 \\
(-0.0003)\end{array}$ & $\begin{array}{r}0.7402 \\
(0.0002)\end{array}$ & $\begin{array}{r}0.5100 \\
(0.0000)\end{array}$ & $\begin{array}{r}0.0000639 \\
(0.0000039)\end{array}$ & $\begin{array}{r}-0.4102 \\
(-0.0002)\end{array}$ \\
\hline Labor/capital & $\begin{array}{r}0.7405 \\
(0.0005)\end{array}$ & $\begin{array}{r}0.5104 \\
(0.0003)\end{array}$ & $\begin{array}{r}0.0000569 \\
(-0.0000031)\end{array}$ & $\begin{array}{r}-0.4101 \\
(-0.0001)\end{array}$ & $\begin{array}{r}0.7403 \\
(0.0003)\end{array}$ & $\begin{array}{r}0.5102 \\
(0.0002)\end{array}$ & $\begin{array}{r}0.0000644 \\
(0.0000044)\end{array}$ & $\begin{array}{r}-0.4100 \\
(0.0000)\end{array}$ \\
\hline $\begin{array}{l}\text { Blended fuel sector } \\
\text { Total }\end{array}$ & $\begin{array}{r}0.7395 \\
(-0.0005)\end{array}$ & $\begin{array}{r}0.5104 \\
(0.0004)\end{array}$ & $\begin{array}{r}0.0000643 \\
(0.0000043)\end{array}$ & $\begin{array}{r}-0.4103 \\
(-0.0003)\end{array}$ & $\begin{array}{r}0.7398 \\
(-0.0002)\end{array}$ & $\begin{array}{r}0.5102 \\
(0.0002)\end{array}$ & $\begin{array}{r}0.0000641 \\
(0.0000041)\end{array}$ & $\begin{array}{r}-0.4104 \\
(-0.0004)\end{array}$ \\
\hline Labor/capital & $\begin{array}{r}0.7405 \\
(0.0005)\end{array}$ & $\begin{array}{r}0.5096 \\
(-0.0004)\end{array}$ & $\begin{array}{r}0.0000551 \\
(-0.000004)\end{array}$ & $\begin{array}{r}-0.4104 \\
(-0.0004)\end{array}$ & $\begin{array}{r}0.7397 \\
(-0.0003)\end{array}$ & $\begin{array}{r}0.5102 \\
(0.0001)\end{array}$ & $\begin{array}{r}0.0000637 \\
(0.0000037)\end{array}$ & $\begin{array}{r}-0.4103 \\
(-0.0003)\end{array}$ \\
\hline Composite good sector & $\begin{array}{r}0.7404 \\
(0.0004)\end{array}$ & $\begin{array}{r}0.5104 \\
(0.0004)\end{array}$ & $\begin{array}{r}0.0000585 \\
(-0.0000015)\end{array}$ & $\begin{array}{r}-0.4102 \\
(-0.0002)\end{array}$ & $\begin{array}{r}0.7397 \\
(-0.0003)\end{array}$ & $\begin{array}{r}0.5098 \\
-(0.0002)\end{array}$ & $\begin{array}{r}0.0000610 \\
(0.0000010)\end{array}$ & $\begin{array}{r}-0.4096 \\
(0.0004)\end{array}$ \\
\hline
\end{tabular}

Notes: Values represent optimal crude oil and cellulosic ethanol taxes/subsidies, for two different elasticity of substitution assumptions and for both revenue constrained $T=0$ and unconstrained cases. Values in parentheses represent the change from the optimal tax/subsidy for each case. All values are expressed in \$/gallon. When the elasticity of substitution in each sector is altered, the remaining sectors retain their default assumption of 0.5 .

${ }^{a}$ Results for Oregon and Idaho exhibited identical patterns of change from the baseline with similar magnitudes. The results are available from the author by request. 
Table 6-Tax, Fuel Production, and Welfare Changes for Varying Cellulosic Ethanol Production Levels: Washington State ${ }^{\mathrm{a}}$

\begin{tabular}{|c|c|c|c|}
\hline & \multicolumn{3}{|c|}{$\begin{array}{l}\text { Cellulosic ethanol production as a } \\
\text { percentage of state-level fuel } \\
\text { consumption }\end{array}$} \\
\hline & Base $(2 \%)$ & $3 \%$ & $4 \%$ \\
\hline \multicolumn{4}{|l|}{ Optimal taxes (\$/gallon) } \\
\hline \multicolumn{4}{|l|}{ Revenue unconstrained } \\
\hline Crude oil & $\$ 0.74$ & $\$ 0.80$ & $\$ 0.88$ \\
\hline Cellulosic ethanol & $\$ 0.51$ & $\$ 0.47$ & $\$ 0.41$ \\
\hline \multicolumn{4}{|l|}{ Revenue-neutral $(T=0)$} \\
\hline Crude oil & $\$ 0.00006$ & $\$ 0.00008$ & $\$ 0.00010$ \\
\hline Cellulosic ethanol & $-\$ 0.41$ & $-\$ 0.38$ & $-\$ 0.33$ \\
\hline \multicolumn{4}{|c|}{ Fuel production (\% change) } \\
\hline \multicolumn{4}{|l|}{ Revenue unconstrained } \\
\hline Blended fuel & $-12.5 \%$ & $-10.7 \%$ & $-8.5 \%$ \\
\hline Cellulosic ethanol & $-15.4 \%$ & $-12.5 \%$ & $-11.3 \%$ \\
\hline \multicolumn{4}{|l|}{ Revenue-neutral $(T=0)$} \\
\hline Crude oil & $-0.0007 \%$ & $-0.0005 \%$ & $-0.0004 \%$ \\
\hline Cellulosic ethanol & $28.5 \%$ & $30.8 \%$ & $33.1 \%$ \\
\hline \multicolumn{4}{|l|}{ Welfare (\% change) } \\
\hline Revenue unconstrained & $0.29 \%$ & $0.25 \%$ & $0.22 \%$ \\
\hline Revenue-neutral $(T=0)$ & $0.00006 \%$ & $0.00006 \%$ & $0.00005 \%$ \\
\hline
\end{tabular}




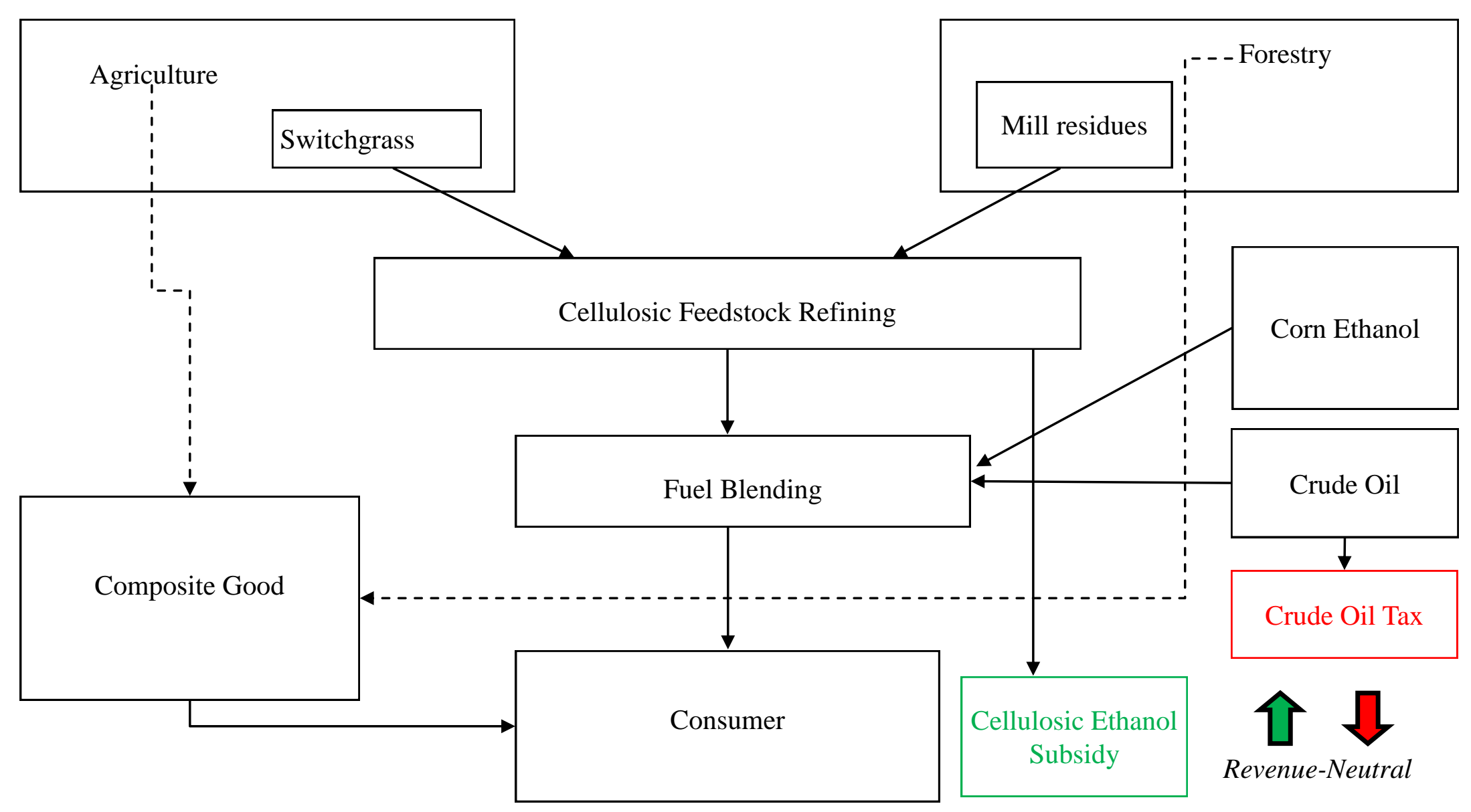

Figure 1. Sectoral Connections in the Production and Consumption of Cellulosic Ethanol 


\section{Appendix}

A.1 Derivation of the optimal revenue-unconstrained tax

In the revenue-unconstrained case, the social planner's optimization problem is given by:

$$
\max _{\left\{\tau^{c}, \tau^{o}\right\}} \Omega=A+\pi^{b}+\tau^{c} Y^{c}+\tau^{o} Y^{o}+W-\delta E
$$

and the associated first-order conditions are given by:

$$
\Omega_{\tau^{k}}=A_{\tau^{k}}+\pi_{\tau^{k}}^{b}+Y^{k}+\tau^{k} Y_{\tau^{k}}^{k}+\tau^{l} Y_{\tau^{k}}^{l}+W_{\tau^{k}}-\delta\left(e^{k} Y_{\tau^{k}}^{k}+e^{l} Y_{\tau^{k}}^{l}\right)=0 \text {, for } k=c, o \text { s.t. } k \neq l .
$$

From the envelope theorem, we have that $\partial \pi^{b} / \partial \tau^{k}=-Y^{k}$ for $k=c, o$ s.t. $k \neq l$. Solving for $\tau^{k}$ yields:

$$
\tau^{k}=\frac{1}{Y_{\tau^{k}}^{k}}\left(-\tau^{l} Y_{\tau^{k}}^{l}-W_{\tau^{k}}-A_{\tau^{k}}+\delta\left(e^{k} Y_{\tau^{k}}^{k}+e^{l} Y_{\tau^{k}}^{l}\right)\right), \text { for } k=c, o \text { s.t. } k \neq l .
$$

Simultaneously solving the system of two equations:

$$
\begin{aligned}
\tau^{k}= & \frac{1}{Y_{\tau^{k}}^{k}}\left\{-Y_{\tau^{k}}^{l}\left[\frac{1}{Y_{\tau^{l}}^{l}}\left(-\tau^{k} Y_{\tau^{l}}^{k}-W_{\tau^{l}}-A_{\tau^{l}}+\delta\left(e^{l} Y_{\tau^{l}}^{l}+e^{k} Y_{\tau^{l}}^{k}\right)\right)\right]\right. \\
-W_{\tau^{k}}-A_{\tau^{k}}+ & \left.\delta\left(e^{k} Y_{\tau^{k}}^{k}+e^{l} Y_{\tau^{k}}^{l}\right)\right\} \Rightarrow \\
\tau^{k}\left(1-\frac{Y_{\tau^{k}}^{l} Y_{\tau^{l}}^{k}}{Y_{\tau^{k}}^{k} Y_{\tau^{l}}^{l}}\right)= & -\frac{Y_{\tau^{k}}^{l}}{Y_{\tau^{k}}^{k} Y_{\tau^{l}}^{l}}\left(-W_{\tau^{l}}-A_{\tau^{l}}+\delta\left(e^{l} Y_{\tau^{l}}^{l}+e^{k} Y_{\tau^{l}}^{k}\right)\right) \\
& +\frac{1}{Y_{\tau^{k}}^{k}}\left(-W_{\tau^{k}}-A_{\tau^{k}}+\delta\left(e^{k} Y_{\tau^{k}}^{k}+e^{l} Y_{\tau^{k}}^{l}\right)\right), \text { for } k=c, o \text { s.t. } k \neq l .
\end{aligned}
$$

Further simplification yields: 


$$
\begin{aligned}
& \tau^{k}=-\left(\frac{Y_{\tau^{k}}^{k} Y_{\tau^{l}}^{l}}{Y_{\tau^{k}}^{k} Y_{\tau^{l}}^{l}-Y_{\tau^{k}}^{l} Y_{\tau^{l}}^{k}}\right) \frac{Y_{\tau^{k}}^{l}}{Y_{\tau^{k}}^{k} Y_{\tau^{l}}^{l}}\left(-W_{\tau^{l}}-A_{\tau^{l}}+\delta\left(e^{l} Y_{\tau^{l}}^{l}+e^{k} Y_{\tau^{l}}^{k}\right)\right) \\
& +\left(\frac{Y_{\tau^{k}}^{k} Y_{\tau^{l}}^{l}}{Y_{\tau^{k}}^{k} Y_{\tau^{l}}^{l}-Y_{\tau^{k}}^{l} Y_{\tau^{l}}^{k}}\right) \frac{1}{Y_{\tau^{k}}^{k}}\left(-W_{\tau^{k}}-A_{\tau^{k}}+\delta\left(e^{k} Y_{\tau^{k}}^{k}+e^{l} Y_{\tau^{k}}^{l}\right)\right) \Rightarrow \\
& \tau^{k}=-\frac{Y_{\tau^{k}}^{l}}{Y_{\tau^{k}}^{k} Y_{\tau^{l}}^{l}-Y_{\tau^{k}}^{l} Y_{\tau^{l}}^{k}}\left(-W_{\tau^{l}}-A_{\tau^{l}}+\delta\left(e^{l} Y_{\tau^{\prime}}^{l}+e^{k} Y_{\tau^{l}}^{k}\right)\right) \\
& +\left(\frac{Y_{\tau^{l}}^{l}}{Y_{\tau^{k}}^{k} Y_{\tau^{l}}^{l}-Y_{\tau^{k}}^{l} Y_{\tau^{l}}^{k}}\right)\left(-W_{\tau^{k}}-A_{\tau^{k}}+\delta\left(e^{k} Y_{\tau^{k}}^{k}+e^{l} Y_{\tau^{k}}^{l}\right)\right) \Rightarrow \\
& \tau^{k}=\delta e^{k}\left(-\frac{Y_{\tau^{k}}^{l} Y_{\tau^{l}}^{k}}{Y_{\tau^{k}}^{k} Y_{\tau^{\prime}}^{l}-Y_{\tau^{k}}^{l} Y_{\tau^{l}}^{k}}+\frac{Y_{\tau^{l}}^{l} Y_{\tau^{k}}^{k}}{Y_{\tau^{k}}^{k} Y_{\tau^{l}}^{l}-Y_{\tau^{k}}^{l} Y_{\tau^{l}}^{k}}\right) \\
& +\delta e^{l}\left(-\frac{Y_{\tau^{k}}^{l} Y_{\tau^{l}}^{l}}{Y_{\tau^{k}}^{k} Y_{\tau^{l}}^{l}-Y_{\tau^{k}}^{l} Y_{\tau^{l}}^{k}}+\frac{Y_{\tau^{\prime}}^{l} Y_{\tau^{k}}^{l}}{Y_{\tau^{k}}^{k} Y_{\tau^{l}}^{l}-Y_{\tau^{\prime}}^{l} Y_{\tau^{l}}^{k}}\right) \\
& -\frac{Y_{\tau^{k}}^{l}}{Y_{\tau^{k}}^{k} Y_{\tau^{l}}^{l}-Y_{\tau^{k}}^{l} Y_{\tau^{l}}^{k}}\left(-W_{\tau^{l}}-A_{\tau^{l}}\right)+\left(\frac{Y_{\tau^{l}}^{l}}{Y_{\tau^{\prime}}^{k} Y_{\tau^{l}}^{l}-Y_{\tau^{k}}^{l} Y_{\tau^{l}}^{k}}\right)\left(-W_{\tau^{k}}-A_{\tau^{k}}\right) \text {, for } k=c, o \text { s.t. } k \neq l \text {. }
\end{aligned}
$$

We can simplify the last expression to write $\tau^{k}$ as:

$$
\tau^{k}=\delta e^{k}+\frac{1}{Y_{\tau^{k}}^{k} Y_{\tau^{l}}^{l}-Y_{\tau^{k}}^{l} Y_{\tau^{l}}^{k}}\left(Y_{\tau^{k}}^{l}\left(W_{\tau^{l}}+A_{\tau^{l}}\right)-Y_{\tau^{l}}^{l}\left(W_{\tau^{k}}+A_{\tau^{k}}\right)\right) \text {, for } k=c, o \text { s.t. } k \neq l .
$$

The reader can verify that if consumer surplus and waiver expenditures were determined exogenously, i.e. $W_{\tau^{k}}=0$ and $A_{\tau^{k}}=0$, the expression for $\tau^{k}$ would reduce to the Pigouvian expression, $\tau^{k}=\delta e^{k}$.

\section{A.2 Derivation of the optimal revenue-neutral tax}

In the revenue-neutral case, the objective function is given by:

$$
\begin{aligned}
& \max _{\left\{\tau^{c}, \tau^{o}\right\}} \Omega=A+\pi^{b}+\tau^{c} Y^{c}+\tau^{o} Y^{o}+W-\delta E, \\
& \text { s.t. } T=\tau^{c} Y^{c}+\tau^{o} Y^{o},
\end{aligned}
$$

with corresponding Lagrangian: 


$$
\mathrm{L}=A+\pi^{b}+\tau^{c} Y^{c}+\tau^{o} Y^{o}+W-\delta E+\lambda\left(T-\tau^{c} Y^{c}-\tau^{o} Y^{o}\right)
$$

The first-order conditions are:

$$
\begin{aligned}
\mathrm{L}_{\tau^{k}} & =A_{\tau^{k}}+\pi_{\tau^{k}}^{b}+Y^{k}+\tau^{k} Y_{\tau^{k}}^{k}+\tau^{l} Y_{\tau^{k}}^{l}+W_{\tau^{k}}-\delta\left(e^{k} Y_{\tau^{k}}^{k}+e^{l} Y_{\tau^{k}}^{l}\right) \\
& -\lambda\left(\tau^{k} Y_{\tau^{k}}^{k}+Y^{k}+\tau^{l} Y_{\tau^{k}}^{l}\right)=0, \text { for } k=c, o \text { s.t. } k \neq l, \\
\mathrm{~L}_{\lambda} & =T-\tau^{c} Y^{c}-\tau^{o} Y^{o} .
\end{aligned}
$$

Solving for $\tau^{k}$ as a function of $\lambda$ gives us:

$$
\begin{aligned}
& \tau^{k}=\frac{1}{(1-\lambda) Y_{\tau^{k}}^{k}}\left(-\tau^{l} Y_{\tau^{k}}^{l}(1-\lambda)-W_{\tau^{k}}-A_{\tau^{k}}-\lambda Y^{k}+\delta\left(e^{k} Y_{\tau^{k}}^{k}+e^{l} Y_{\tau^{k}}^{l}\right)\right), \\
& \text { for } k=c, o \text { s.t. } k \neq l .
\end{aligned}
$$

Similar to the previous derivation, we simultaneously solve the system in (10) to obtain:

$$
\begin{aligned}
& \tau^{k}=\frac{\delta}{1-\lambda} e^{k}+\frac{1}{Y_{\tau^{k}}^{k} Y_{\tau^{l}}^{l}-Y_{\tau^{l}}^{k} Y_{\tau^{k}}^{l}}\left(Y_{\tau^{k}}^{l} \frac{W_{\tau^{l}}+A_{\tau^{l}}-\lambda Y^{l}}{1-\lambda}-Y_{\tau^{l}}^{l} \frac{W_{\tau^{k}}+A_{\tau^{k}}-\lambda Y^{k}}{1-\lambda}\right), \\
& \text { for } k=c, o \text { s.t. } k \neq l .
\end{aligned}
$$

To derive the optimal value of $\lambda$, we substitute the previous equation into the revenue constraint and solve for $\lambda$ :

$$
\begin{aligned}
T(1-\lambda) & =Y^{o}\left(\delta e^{o}+\frac{1}{Y_{\tau^{o}}^{o} Y_{\tau^{c}}^{c}-Y_{\tau^{c}}^{o} Y_{\tau^{o}}^{c}}\left(Y_{\tau^{o}}^{c}\left(W_{\tau^{c}}+A_{\tau^{c}}-\lambda Y^{c}\right)-Y_{\tau^{c}}^{c}\left(W_{\tau^{o}}+A_{\tau^{o}}-\lambda Y^{o}\right)\right)\right) \\
& +Y^{c}\left(\delta e^{c}+\frac{1}{Y_{\tau^{c}}^{c} Y_{\tau^{o}}^{o}-Y_{\tau^{o}}^{c} Y_{\tau^{c}}^{o}}\left(Y_{\tau^{c}}^{o}\left(W_{\tau^{o}}+A_{\tau^{o}}-\lambda Y^{o}\right)-Y_{\tau^{o}}^{o}\left(W_{\tau^{c}}+A_{\tau^{c}}-\lambda Y^{c}\right)\right)\right) .
\end{aligned}
$$

Solving for $\lambda$ : 


$$
\begin{aligned}
T(1-\lambda) & =\frac{\lambda}{Y_{\tau^{o}}^{o} Y_{\tau^{c}}^{c}-Y_{\tau^{c}}^{o} Y_{\tau^{o}}^{c}}\left(Y^{o}\left(Y_{\tau^{c}}^{c} Y^{o}-Y^{c} Y_{\tau^{o}}^{c}\right)+Y^{c}\left(Y_{\tau^{o}}^{o} Y^{c}-Y^{o} Y_{\tau^{c}}^{o}\right)\right) \\
& +Y^{o}\left(\delta e^{o}+\frac{1}{Y_{\tau^{o}}^{o} Y_{\tau^{c}}^{c}-Y_{\tau^{c}}^{o} Y_{\tau^{o}}^{c}}\left(Y_{\tau^{o}}^{c}\left(W_{\tau^{c}}+A_{\tau^{c}}\right)-Y_{\tau^{c}}^{c}\left(W_{\tau^{o}}+A_{\tau^{o}}\right)\right)\right) \\
& +Y^{c}\left(\delta e^{c}+\frac{1}{Y_{\tau^{c}}^{c} Y_{\tau^{o}}^{o}-Y_{\tau^{o}}^{c} Y_{\tau^{c}}^{o}}\left(Y_{\tau^{c}}^{o}\left(W_{\tau^{o}}+A_{\tau^{o}}\right)-Y_{\tau^{o}}^{o}\left(W_{\tau^{c}}+A_{\tau^{c}}\right)\right)\right)
\end{aligned}
$$

Simplifying the previous expression and isolating $\lambda$ :

$$
\lambda^{*}(T)=\frac{T-\left(Y^{o} \delta e^{o}+Y^{c} \delta e^{c}\right)-\frac{\left(W_{\tau^{c}}+A_{\tau^{c}}\right)\left(Y^{o} Y_{\tau^{o}}^{c}-Y_{\tau^{o}}^{o} Y^{c}\right)+\left(W_{\tau^{o}}+A_{\tau^{o}}\right)\left(Y^{c} Y_{\tau^{c}}^{o}-Y_{\tau^{c}}^{c} Y^{o}\right)}{Y_{\tau^{o}}^{o c}-Y_{\tau^{c}}^{o} Y_{\tau^{o}}^{c}}}{T+\frac{Y^{o}\left(Y_{\tau^{c}}^{c} Y^{o}-Y^{c} Y_{\tau^{o}}^{c}\right)+Y^{c}\left(Y_{\tau^{o}}^{o} Y^{c}-Y^{o} Y_{\tau^{c}}^{o}\right)}{Y_{\tau^{o}}^{o} Y_{\tau^{c}}^{c}-Y_{\tau^{c}}^{o} Y_{\tau^{o}}^{c}}} .
$$

A.3 Derivative of consumer surplus with respect to $\tau^{k}$

We can write the derivative of consumer surplus with respect to $\tau^{k}$ in the following way:

$$
\begin{aligned}
\frac{\partial A}{\partial \tau^{k}} & =\frac{\partial}{\partial \tau^{k}}\left(v\left(p^{b}\left(\tau^{k}, \tau^{l}\right), I\right)-p^{b}\left(\tau^{k}, \tau^{l}\right) B\left(\tau^{k}, \tau^{l}\right)-X\left(\tau^{k}, \tau^{l}\right)\right) \\
& =\frac{\partial}{\partial \tau^{k}}\left(u\left(B\left(\tau^{k}\right), X\left(\tau^{k}\right)\right)-p^{b}\left(\tau^{k}\right) B\left(\tau^{k}\right)-X\left(\tau^{k}\right)\right) \\
& =u_{B} \frac{\partial B}{\partial \tau^{k}}+u_{X} \frac{\partial X}{\partial \tau^{k}}-p^{b} \frac{\partial B}{\partial \tau^{k}}-\frac{\partial p^{b}}{\partial \tau^{k}} B-\frac{\partial X}{\partial \tau^{k}} \\
& =\left(u_{B}-p^{b}\right) \frac{\partial B}{\partial \tau^{k}}+\left(u_{X}-1\right) \frac{\partial X}{\partial \tau^{k}}-B \frac{\partial p^{b}}{\partial \tau^{k}} \\
& =-B \frac{\partial p^{b}}{\partial \tau^{k}}, \text { for } k=c, o .
\end{aligned}
$$

